\title{
DEMONSTRATIVES IN SPACE AND INTERACTION: DATA FROM LAO SPEAKERS AND IMPLICATIONS FOR SEMANTIC ANALYSIS
}

\author{
N. J. ENFIELD \\ Max Planck Institute for Psycholinguistics, Nijmegen
}

\begin{abstract}
The semantics of simple (i.e. two-term) systems of demonstratives have in general hitherto been treated as inherently spatial and as marking a symmetrical opposition of distance ('proximal' versus 'distal'), assuming the speaker as a point of origin. More complex systems are known to add further distinctions, such as visibility or elevation, but are assumed to build on basic distinctions of distance. Despite their inherently context-dependent nature, little previous work has based the analysis of demonstratives on evidence of their use in real interactional situations. In this article, video recordings of spontaneous interaction among speakers of Lao (Southwestern Tai, Laos) are examined in an analysis of the two Lao demonstrative determiners $n i i^{4}$ and $n a n^{4}$. A hypothesis of minimal encoded semantics is tested against rich contextual information, and the hypothesis is shown to be consistent with the data. Encoded conventional meanings must be kept distinct from contingent contextual information and context-dependent pragmatic implicatures. Based on examples of the two Lao demonstrative determiners in exophoric uses, the following claims are made. The term $n i i^{4}$ is a semantically general demonstrative, lacking specification of ANY spatial property (such as location or distance). The term $\operatorname{nan}^{4}$ specifies that the referent is 'not here' (encoding 'location' but NOT 'distance'). Anchoring the semantic specification in a deictic primitive 'here' allows a strictly discrete intensional distinction to be mapped onto an extensional range of endless elasticity. A common 'proximal' spatial interpretation for the semantically more general term $n i i^{4}$ arises from the paradigmatic opposition of the two demonstrative determiners. This kind of analysis suggests a reappraisal of our general understanding of the semantics of demonstrative systems universally. To investigate the question in sufficient detail, however, rich contextual data (preferably collected on video) is necessary.*
\end{abstract}

1. The Semantics of Demonstratives. Demonstratives are one of the great puzzles of linguistic science. They represent perhaps the archetypal case of the linguistic system being grafted onto the physical world. But the semantics of demonstratives remain poorly understood (despite advances in their typological description; Fillmore 1982:

\footnotetext{
* Many of the ideas proposed here have their origin in collaborative research on space in language and cognition conducted by members of the Space Project of the Language and Cognition Group, Max Planck Institute for Psycholinguistics, Nijmegen. Those who have contributed to research on demonstratives within the group since 1996 include Steve Levinson, Eric Pedersen, David Wilkins, Gunter Senft, Felix Ameka, Jürgen Bohnemeyer, Melissa Bowerman, Penny Brown, Michael Dunn, James Essegbey, Raquel Guirardello, Birgit Hellwig, Elizabeth Keating, Sotaro Kita, Anna Margetts, Sergio Meira, Asli Özyürek, Angela Terrill, and Barbara Villanova. These researchers are responsible for many of the insights about the semantics and pragmatics of demonstratives that originally motivated the research reported on here, and that have found their way into my own analysis of Lao (see Wilkins 1999). I am fortunate to be able to conduct research in this environment. I gratefully acknowledge financial support from the Max Planck Society, and in particular technical support from the Technical Group of the Max Planck Institute for Psycholinguistics for assistance with field equipment and for providing the technical means for conducting the kind of research reported on here. I also thank my Lao informants (especially Pitsana Vayaphanh) for allowing me to videotape them in action and to publicize the results. For helpful comments on earlier drafts of this report I sincerely thank Martina Faller, Sotaro Kita, Sergio Meira, David Wilkins, Steve Levinson, Jürgen Bohnemeyer, Konstanze Jungbluth, Eleni Kriempardis, the editors of Language, and two anonymous referees. I have not always followed these commentators' suggestions, and they may therefore be exempt from blame for any infelicities of this work.

The illustrations in this report are still images taken from hand-held video recordings of spontaneous interaction, mostly in outdoor settings. They allow a relatively direct depiction of the spatial orientation of interlocutors, and spatial relations between them and the places and objects which are referred to in their speech. The films were made using a digital video camera ( 24 frames per second) under natural light. I am grateful to Alex Dukers for his help in preparation and annotation of the images.
} 
47ff, Anderson \& Keenan 1985, Himmelmann 1996, Diessel 1999), primarily because demonstratives have seldom been examined in situ. Due to the inherently contextbound character of demonstratives, it is necessary to examine their use in spontaneous interaction, in all its richness. Such a method is pursued in this study, using data from video recordings of natural interaction among speakers of Lao (Southwestern Tai, Laos), as spoken around the city of Vientiane. While the Lao demonstrative determiner system is typologically unremarkable (a two-term system opposing so-called proximal and distal), a traditional analysis - assuming a symmetrical opposition of 'distance' marking between the two terms - fails. Close attention to distributional facts and the pragmatics of interlocutors' interpretations of physical space in interaction (including contingent factors like attention, common ground, cultural and personal conceptions of space) supports a lean semantic analysis of the two demonstratives, whereby neither encodes 'distance' (i.e. neither makes specification of notions such as 'near' or 'far'), and only one encodes 'location' (namely the semantically more specific 'distal' demonstrative, which refers to something 'not here'). The proposed semantics are minimal, yet they remain consistent with the use of these forms in rich contexts. I suggest that similar analyses are likely to hold for other such typologically unremarkable systems (such as English this and that).

I begin here by introducing the view of linguistic meaning adopted in this analysis. While it may be that only a minimal proportion of a given utterance's whole meaning is semantically ENCODED, one cannot verify the content of that encoded component nor understand the principles of its use without studying the contingent details of interactional context, monitoring the input of information from the speech situation, and the resultant enrichment of encoded meaning by inference. I argue (\$2) that in order to understand what is conveyed in total in an interaction, a Gricean distinction between encoded semantics and defeasible implicature is necessary. Maintaining such a distinction helps to highlight the importance of context-given information and context-derived inference in computing the overall meanings of linguistic utterances.

2. Meaning, context, and the Semantics/Pragmatics distinction. The analysis of the demonstrative system of Lao to be presented here justifies the recognition of a distinction between effectively context-independent encoded meanings for linguistic signs, on the one hand, and qualitatively distinct contextual information and contextspecific inferences, on the other. This view puts context, culture, and cognition at the heart of linguistic meaning, yet its merits have been overlooked in some recent traditions of research on linguistic meaning. It is thus necessary to preface the analysis with a few remarks on theoretical background.

Meaning arises when a perceptible artifact, such as a sight or a sound, is interpreted by an observer to STAND FOR something (Peirce 1965/1932:135). The relation of STANDING FOR is not inherent in a signal, but is actively derived by an interpreting individual. From exposure to some signal $p$, one may conceive of $q$, either due to $q$ 's likeness to $p$ (iconicity), by spatiotemporal association of $q$ with $p$ (indexicality), or by predetermined social agreement that $q$ will be the meaning of $p$ (symbolism; Peirce 1965/1932:143). These distinctions do not denote types of signs, but manners of signification. Individual signs often combine more than one.

Let us consider symbolic meaning. A sign is a SYMBOL if its relation of STANDING FOR is determined by a precedent of social agreement, and not by any relationship of formal likeness or 'dynamical connection' between form and meaning. ${ }^{1}$ I use the terms

\footnotetext{
${ }^{1}$ This does not mean that the form of a symbol cannot have some likeness to its meaning. Consider onomatopoeic expressions like cock-a-doodle-doo. In this case, the form-meaning relationship holds not
} 
INTENSION and SEMANTIC MEANING interchangeably to refer to the symbolic meaning that a linguistic sign conventionally encodes. The SEMANTIC INVARIANT of a linguistic sign is the minimal meaning that is always derived from the signal regardless of the context in which it is used. Some have expressed unease with this view, claiming that it implies that linguistic signs are 'objectively real entities' (Lakoff 1987:171). But an analytical commitment to the idea of encoded symbolic meaning does not entail a view that a sign has a Platonic reality independent of those individuals who hold the idea of that sign. Peirce observed that 'the word lives in the minds of those who use it' (Peirce 1965/1932:169) and repeatedly asserted that meaning cannot arise without an active mind deriving it. Nevertheless, it is EFFECTIVELY the case that linguistic signs have stable and context-independent meanings. This is explained by the mechanism of CONVENTION, which may be defined as 'a community's solution to a recurrent coordination problem' (Clark 1996:70; after Schelling 1960, Lewis 1969). The coordination problem relevant to the present discussion is the need for interlocutors-who lack direct access to each other's minds - to reliably converge on mutual understandings of each other's intentions and interpretations in talk (Clark 1996). An individual's representation of a linguistic meaning is a private hypothesis, but the public contract of convention results in the effective convergence, across a population, of individuals' personal hypotheses about the concept encoded in a word. ${ }^{2}$ This 'intercalibration of idiolects' (Hockett 1987:106-7, 157-58; cf. Lee 1996:227-28) allows us to trust that meanings will be stable across contexts, to predict their effects, and to be confident of what will and will not go ON RECORD when a given sign is used. The public stability of a semantic representation is not independent of human interaction, but arises from communitywide ‘joint action' (as described by Clark (1996:59ff)).

The domain of PRAGMATICS concerns the process whereby meanings richer than the encoded conventional meanings of signs arise in real contexts. Pragmatic meanings are semiotically accessible and/or logically derivable, but are not semantically encoded. They include contingent aspects of context and common ground (things one knows, and things one can see and hear), on the one hand, and derived inferences on the other. Context and common ground constitute input for deriving inferences from encoded meanings. Clark defines two people's COMMON GROUND as 'the sum of their mutual, common, or joint knowledge, belief, and suppositions’ (1996:93). This knowledge, shared and mutually known to be shared among interlocutors, may be freely assumed for the purpose of calculating inferences. The term IMPLICATURE refers to the process or product of such inferences. Implicatures are contingent and context-dependent, arising from given common ground, including speakers' knowledge of the linguistic system, and associated expectations of what a speaker 'could have said' but didn't (Grice 1975, Levinson 2000). While a linguistic sign may have one implicature in one context, that implicature may simply not arise in another context. Semantic meaning, by contrast, is derived regardless of the context. A final notion coming under the rubric of pragmatics is EXTENSION (in the sense of Carnap 1947). The extension of a linguistic sign is the array of things, events, or situations to which it can be taken to refer.

BECAUSE OF a formal likeness between the phonological string and the conceived sound of a rooster crowing, but because of a social agreement that just this string will have just this meaning. This is why the soundmeaning pairing is not predictable (despite being 'motivated'-cf. French cocorico).

${ }^{2}$ Language acquisition involves hypothesis construction, and in adult life our established models of linguistic meanings still remain hypotheses, which are repeatedly tested (and potentially revised) whenever we utter or hear linguistic signs. 
The insight that meaning is derived from linguistic signs in qualitatively distinct ways has led to the most important working distinction for the analysis of how linguistic forms are used in conveying and deriving meaning, namely the distinction between (effectively) ENCODED meaning, on the one hand, and all other contingent meaning, on the other (Levinson 1995:222). This view of meaning forces us to examine given signs in their usage across a wide variety of contexts. In order to verify hypotheses about the semantic invariant of a linguistic expression, one MUST consider the interaction between context and encoded meaning. The rich details of context, which constitute input for implicatures, are as important in the analysis as the encoded semantics. ${ }^{3}$ While it is necessary to separate context-independent meaning (encoded semantics) from context-dependent meaning (pragmatics), these aspects of the full repertoire of meaningconveying mechanisms used by speakers are complementary and interdependent, and therefore must be studied simultaneously.

3. DeIXIs. Deictic expressions depend inherently on context for interpretation of reference (Lyons 1968:275ff, Fillmore 1997[1971], Clark et al. 1983, Hanks 1990). Nevertheless, as Bühler (1982[1934]) established, deictic expressions have a contextfree dimension, namely the idea of a stable 'deictic centre' or 'origo', which anchors simple notions 'I', 'here', and 'now'. Bühler pointed out (as others have since done; for example, Wierzbicka 1996) that these are not semantically decomposable. ${ }^{4}$ Being challenged to define them will either 'induce the language theorist into esoteric philosophical abysses or to respectful silence' (Bühler 1982[1934]:13). Accordingly, I regard 'I', 'here', and 'now' as semantically primitive (Wierzbicka 1996: ch. 2, cf. 1972:16). In addition to Bühler's core deictic domains of person, place, and time, there is a further stable and simple deictic notion, namely a primitive demonstrative meaning, a symbolic INDICATING function which I gloss here as DEM. ${ }^{5}$ This meaning cannot be reduced or

\footnotetext{
${ }^{3}$ That one can believe in encoded meaning and maintain this view has been missed by certain critics of the semantics-pragmatics distinction. Consider, for example, the claim that adoption of a semantics-pragmatics distinction implies a belief that semantics is 'much more philosophically important than pragmatics' (Lakoff 1987:171). This exemplifies a general failure of the recent cognitive linguistics tradition-despite its significant contributions to the study of meaning - to recognize the importance of different semiotic functions (à la Peirce 1965/1932). Casad (1988), for example, lumps all signification under the heading of MEANING, stating that 'the meaning of linguistic expressions is context defined and includes all aspects of the information that are relevant to describing particular conceived situations' (Casad 1988:347). Note, however, that some cognitive linguists are beginning to explicitly acknowledge distinct levels of meaning. Langacker (1987: 154) once rejected the pragmatics/semantics distinction, but in a more recent discussion of 'context and cognitive semantics' (Langacker 1997), he talks of a language 'code', referring to meaning that is 'schematic at the level of established linguistic convention' (Langacker 1997:234), stating that such coded schematic meaning then takes on 'a specific value when instantiated in a particular instance of language use' (234). This is none other than a distinction between effectively encoded context-free meaning, on the one hand, and genuinely context-dependent inferred meaning, on the other. It is encouraging to see recognition within the cognitive linguistics tradition that information acquired and/or derived on the basis of a sign IN CONTEXT is not necessarily generalizable as part of THE VALUE OF THE SIGN ITSELF. For further discussion of these points, see Grice 1989, Levinson 1995:210, 1997, Wilkins \& Hill 1995:212-14, 252-53.

${ }^{4}$ This nondecomposability is at the level of INTENSIONAL MEANING and is criterial of the status of a semantic meaning as PRIMITIVE (Goddard 1998). An anonymous referee rightly points out that the 'global meaning' of demonstratives in their situated usage can be very complex indeed, as examples described in this article illustrate. My argument is that this global meaning is highly context-enriched and is not equal to the stable schematic encoded core meaning of the expression.

${ }^{5}$ This is a technical term, mnemonic for DEMONSTRATIVE. It could also be glossed by the semantically most general demonstrative in a language. I choose not to use an English demonstrative to gloss it, since there is disagreement about which English term is the unmarked one (compare Halliday and Hasan (1976: 59) who claim that as basic with Wierzbicka (1980:27) who claims this as basic).
} 
expressed in terms of some other feature of the origo, and is simply an essential indicating expression. It is abstract with respect to an exophoric/endophoric distinction (Himmelmann 1996, pace Halliday \& Hasan 1976:59, Diessel 1999:93ff). It is useful for drawing attention, but attention-direction is not a semantically specified function. Its use presupposes that an addressee can know what it is referring to. The following section elaborates on the nature of the DEM function, which I suggest is at the semantic core of any demonstrative.

3.1. Demonstratives. Demonstratives are often associated with indexicality in physical space, but they do not necessarily encode spatial meanings. They can be used in a range of domains. Himmelmann (1996) establishes four major functions of demonstratives crosslinguistically: situational, discourse, anaphoric, and recognitional deixis (cf. Lakoff 1974, Diessel 1999). The situational usage, involving 'reference to entities in the surrounding situation', has been referred to as EXOPHORIC (Halliday \& Hasan 1976:33, Diessel 1999:6) and has traditionally been treated as primary with respect to other, ENDOPHORIC functions such as discourse and recognitional deixis. Diessel, like others before him, claims that the exophoric use of demonstratives is 'the basic use from which all other uses derive' (1999:93). Diessel's arguments, however, appealing to grammaticalization, acquisition, and markedness, do not establish 'basicness' at the level of SYNCHRONIC ADULT SEMANTICS. I follow Himmelmann (1996: 223,242 ) in maintaining a monosemy bias and regarding the simplest demonstrative meanings as general with respect to exophoric versus endophoric reference. The exophoric use of a semantically general demonstrative is one DOMAIN OF APPLICATION (i.e. part of the term's EXTENSION), not a distinct SEMANTIC MEANING (i.e. not specified at the INTENSIONAL level). This is possible because a referent is always a CONCEPTUAL entity, irrespective of whether it is instantiated in the situational context or in the linguistic discourse.

The basic function of demonstratives is not to specify wHERE something is, but rather to specify WHICH ONE you are talking about (see Fillmore 1982:43-44). I cannot rely on a demonstrative to provide the content for a reply to a where question. Thus, if I ask you Where is my copy of War and Peace?, you cannot answer by saying This book or This one.

When I use a demonstrative-for example, by asking Have you read this book?, with reference to War and Peace, sitting with other books on a table between us-you and I have a COORDINATION PROBLEM (Schelling 1960, Lewis 1969, Clark et al. 1983). We need to identify one and the same book, and we need to rely on each other to do so in the situation. My use of the word this alone is not enough for our problem to be solved. Its core meaning 'DEM' announces that I assume we can converge on a solution to the problem, given information accessible to both of us. Speakers and listeners both assume a kind of conversational maxim which Clark, Schreuder, and Buttrick call the 'principle of optimal design': 'The speaker designs his utterance in such a way that he has good reason to believe that the addressees can readily and uniquely compute what he meant on the basis of the utterance along with the rest of their common ground' (Clark et al. 1983:246). ${ }^{6}$ This means that speakers will not intentionally invite inferences

\footnotetext{
${ }^{6}$ That a speaker may intentionally be vague or misleading does not refute the idea of such a principle. The presupposition referred to here functions as a MAXIM, not as a RULE. It is a 'presumptive heuristic', which 'informs (rather than strictly governs) conversation' (Levinson 2001). The key to understanding this point is that the maxim is less a rule for the SPEAKER to follow than it is a rule for the ADDRESSEE to ASSUME that the speaker follows.
} 
that would require information unavailable to their addressees. Accordingly, addressees assume that speakers will have tailored their inference-inviting utterances to make reference only to information known to be in common ground (that is, information not just shared between speaker and addressee, but known by each to be so shared; D'Andrade 1987:113, Clark 1996:92ff, Enfield 2000:45). ${ }^{7}$ Suppose that by saying this book I mean 'the copy of War and Peace sitting on the table here now'. You may figure this out as a result of some mutually obvious perceptual salience of the book, of our current shared focus of attention on the book, of my physically positioning the book in your field of attention (by holding it up, for example), or of my directing your attention to the book (perhaps by pointing at it; Clark 1996, 2003). In another situation, the book may not be perceptually accessible at all, but nonetheless salient enough (e.g. in the current focus of conceptual attention in the discourse) to provide us with a mutually unique solution. The basic demonstrative MEANING does not encode the idea of which book 'this book' is (in this case, War and Peace).

All languages have at least one demonstrative determiner, and there is almost always a second term, often a third, and sometimes more (Anderson \& Keenan 1985, Diessel 1999). This adds further dimensions to the process of interpretation of a single demonstrative described by Clark, Schreuder, and Buttrick (1983). A semantic distinction encoded in a second demonstrative term provides the addressee with an additional clue for solving the coordination problem of reference. It seems that the most common meaning added by a second term is spatial. When a semantically more specific demonstrative comes into paradigmatic opposition with a semantically more general one, important system-internal pragmatic effects arise, and these are not recognized in standard typological accounts of demonstratives (Lyons 1977, Anderson \& Keenan 1985, Diessel 1999). While standard analyses depict pairs like this and that as symmetrically expressing the notions 'near speaker' and 'far from speaker', respectively, the symmetry may be an illusion. Instead, the two terms may form an ENTAILMENT SCALE Or INFORMATIVENESS SCALE (Levinson 2000:79), whereby the use of a semantically less specific or 'weaker' form (given that a semantically more specific or 'stronger' form is an option in the same grammatical context) implies the converse of the stronger form, yet without semantically encoding it. Thus, as I argue below, since $\operatorname{nan}^{4}$ ENCODES "not here', $n i i^{4}$ often IMPLIEs that the referent is something 'here'. ${ }^{8}$ But the two terms show different degrees of semantic specificity.

Within the realm of spatial meaning, as specified for example by a semantically more specific demonstrative, it is crucial to distinguish a semantic specification of LOCATION from one of DISTANCE. Semantic content can specify wHERE something is without specifying HOW FAR AWAY it is. This point is often overlooked, for example by Diessel (1999: ch. 3 passim), who equates 'indicating location' with 'indicating distance', and in addition does not consistently distinguish these from 'deictic function'. However, these three things are logically distinct, and this point is crucial to the analysis of Lao demonstratives proposed here.

\footnotetext{
${ }^{7}$ Note, however, recent work by Keysar, Barr, Balin, and Brauner (2000) arguing that addressees occasionally 'consider some referents from their own perspective, even when they know that these referents are inaccessible to the speaker' (Keysar et al. 2000:37). It is not clear, however, whether this has consequences for the idea of the 'optimal design principle' as I apply it here.

${ }^{8}$ The superscript numeral on Lao words represents lexical tone. Tone 4 is a high falling tone -51 in Chao's (1930) 'tone letter' schema. Other tones are 1 (32), 2 (35), 3 (13), 5 (31).
} 
While the Lao demonstratives $n i i^{4}$ and $n a n^{4}$ can serve both exophoric and endophoric functions, discussion here is restricted to exophoric uses only, essentially due to space limitations. The data used are from video recordings of spontaneous interaction among Lao speakers in situations that involve reference to, and manipulation of, real objects in interactional space. This method of investigation into demonstratives is necessary in order to remedy the problems of standard analyses. In complement to these naturally occurring examples, I have also discussed these scenes with consultants and have sometimes asked for judgments as to whether another demonstrative could have been used. Further, I applied an elicitation technique for probing demonstrative distinctions by setting up situations depicted in a set of drawings (Wilkins 1999), covering a range of hypothetical scenarios designed to vary with respect to proximity of a concrete referent - such as a book - to speaker and addressee, at various distances and in various conditions (see van Geenhoven \& Warner 1999:56). The technique works especially well when the situation elicits a judgment that only one demonstrative is possible. In most cases, however, speakers report that either demonstrative could conceivably be used (although one may be preferred). The problem here is that on any given occasion, speakers DO NOT use either-they must and do select one. The choice is not arbitrary, but is a function of the semantics of the alternative demonstratives, IN COMBINATION WITH rich contextual factors. ${ }^{9}$ Speakers' a priori intuitions are that $n i i^{4}$ is used for things near the speaker, while $\operatorname{nan}^{4}$ is used for things far from the speaker, but observational data show that referents of 'proximal' nii ${ }^{4}$ are often quite far away, indeed as far or further than many referents of 'distal' $n a n^{4}$. Similarly, things marked by distal $n a n^{4}$ may be physically very close to the speaker. ${ }^{10}$ Precisely the same is the case for English this and that.

A central point in understanding how demonstratives are used in exophoric functions is that human interaction transforms merely physical space into MEANINGFUL space. This cannot be measured by observing purely physical spatial properties of interactional scenes. Interlocutors monitor and model each other's mental states (Goody 1995, Clark 1996), and this includes their construals of physical space as controlled, possessed, shared, separated, and so on, by one another. To gain insight into this phenomenon, it is necessary to look at real examples of demonstrative use in all their richness.

3.2. The EXTENSIONAL RANGE OF 'HERE'. My semantic analysis of the marked demonstrative in Lao assumes a basic spatial meaning 'here', which is a primitive deictic notion given by the deictic center or origo. While I can use here to refer to places of seemingly arbitrary extension - the universe, the earth, the city of Nijmegen, Office 267, a place on the bottom right corner of my front tooth - the IDEA of 'here' remains conceptually discrete. The intension of 'here' is A PLACE, prototypically 'where I am now'. When I say John's here I tell you WHERE he is, but not HOW FAR AWAY. Physical measurements of specific context-situated spatial extensions of the word here would tell us little about its intension. Instead, it is necessary to consider properties of the

\footnotetext{
${ }^{9}$ David Wilkins points out that the choice sometimes Is arbitrary. That is, when the conditions are such that either of the demonstratives would lead equally well to the right unique solution to the current coordination problem, then it doesn't matter which one you use.

${ }^{10}$ A referee suggests making reference here to the notion of 'prototype'. It is interesting that when asked out of context to explain the use of $n i i^{4}$ and $n a n^{4}$, consultants typically say that the terms refer to referents that are 'near' and 'far', respectively. But as examples in this paper show, there is no consistent correspondence between demonstrative selection and physical distance between speaker and referent. The approach to linguistic meaning I adopt here allows prototype effects to arise in usage without entailing elasticity of SEMANTIC MEANING (Wierzbicka 1990).
} 
speech location not as mere space but as INTERACTIONAL SPACE, partly in terms of physical attributes of the space itself (including spatial arrays which speakers form with their bodies and other props as they interact; Scheflen 1976), but most importantly, in terms of phenomena affecting the INTERPRETATION of space emerging from the dynamics of the human interaction itself (Goffman 1963, Kendon 1977).

People interact in places like rooms, buses, fields, gardens, and shops. There are physical boundaries within these places (doorways, walls, or vegetation), which do not absolutely prevent communication across them, but which are nevertheless regarded as social boundaries, and are treated as if they were true physical barriers to communication (Goffman 1963:151ff). People physically orient themselves in space to create interactional closure (Kendon 1977: ch. 5; see also Scheflen 1976) and, thus, effective boundaries to communication. These spatial closures emerge from, and are defined by, joint communicative activity and are in the minds and manners of people rather than in the physical setting itself. Logically independent of such closures, but often coinciding with them, is a conceptually defined area that may be called the HERE-SPACE. The herespace is not necessarily defined with reference to physical facts, but is simply the place or area which one considers as 'here' at a particular moment for a particular purpose. Directly analogous to the puzzle of how interlocutors use demonstrative reference to solve coordination problems of reference is the puzzle of how interlocutors coordinate their convergent understanding of the perimeter of 'here' at a given moment.

Just one of the factors that can define a speaker's here-space is his or her ENGAGEMENT AREA, the place which is, at moment $t$, the conceived site of a person's currently dominant manual and attentional engagement. ${ }^{11}$ The factors that determine the perimeter of a person's engagement area during interaction are many and varied, and constantly competing. The perimeter of one's engagement area shifts constantly, from moment to moment, like a fluid and invisible shell encircling specific configurations of people and things in space. Suppose that I am one of two people standing talking at a cocktail party. We face each other, creating a tight engagement area. If we are joined by a third, we broaden our focus, and our encircling shell reshapes (as we step back to include the new interlocutor), then re-cohering (or being reconstituted), now larger, around the three of us as we form a fresh symmetrical array (Kendon 1977: ch. 5). When I approach a market table and enter into discussion with a merchant-who is facing me on the other side of the table-about the price of an item lying on the table between us, an engagement area is created, embracing the two of us and our mutual focus of engagement, the item to be purchased. When the sale is made and the merchant turns to wrap the item, her visual and manual preoccupation with that task causes the previous twoperson engagement area to fade out, and her adjusted focus creates a new SOLO-ENGAGEMENT area, now much smaller, momentarily excluding me and the table with goods on it (see $\$ 5.1$ below). ${ }^{12}$

In interactional spaces, such as the open marketplaces in which many of the examples described in this paper were collected, people continually monitor the dynamic activa-

\footnotetext{
${ }^{11}$ Kendon describes something similar in what he calls the TRANSACTIONAL SEGMENT: the 'space extending in front of a person ... which he is currently using in whatever his current activity may be', 'the space into which he looks and speaks, into which he reaches to handle objects', which he will 'endeavor to maintain' (Kendon 1977:181). The transactional segments of two interlocutors may 'overlap to create a joint transactional space' (181).

${ }^{12} \mathrm{I}$ am assuming that no more than one engagement area can be dominant at any one moment, although of course there can be a number semi-active or implicit. Thus, the engagement area bridging the market table is soon resumed after the merchant is finished with her momentary solo-engagement in wrapping the purchased item.
} 
tion of engagement areas and the interactional borders they create. ${ }^{13}$ This conception of interactionally established perimeter interacts with referent location, resulting in a number of logical possibilities of relevance to the selection of demonstratives, to be examined below. An object (e.g. a book) that a speaker wants to refer to with a demonstrative may or may not be in his or her own engagement area at the relevant moment. Also, the engagement areas of speaker and addressee may or may not overlap at the relevant moment.

The engagement area perimeter is just one possible determinant of the more abstract here-space perimeter, and as I argue below, it is the here-space perimeter that is directly relevant for demonstrative selection. (Sharing an engagement area at a given moment does not entail sharing a here-space.) The logical possibilities for coincidence of location of a referent, speaker's here-space, and addressee's here-space are shown in Table 1.

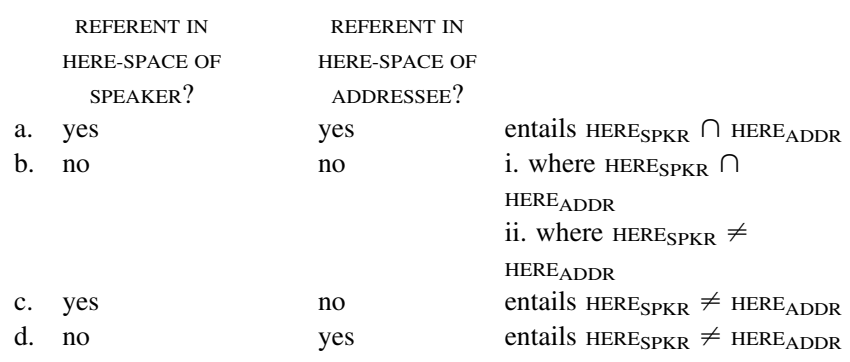

TABLE 1. Logical possibilities for coincidence of location of referent, speaker's here-space, and addressee's here-space.

There are a number of interactional reasons for speakers to make the construals they do, when they do. For instance, one's choice of demonstrative can signal a claim about whether one's 'here' and the 'here' of one's addressee are shared. This can be influenced by strongly suggestive aspects of the physical situation, by subtleties of the social situation (e.g. distinctions arising out of politeness - it may be impolite to assume one's space to be shared with that of one's addressee), or by deliberate manipulation. But ultimately the choice is made by the speaker with the intention that the demonstrative selected be the one most likely to result in the coordination problem of reference being solved by the addressee's convergence with the speaker on the right referent.

Let us now consider the Lao system of demonstratives, in particular the two demonstrative determiners $n i i^{4}$ and $n a n^{4}$.

4. LAO DEMONSTRATIVE DETERMinERS $n i i^{4}$ AND $n a n^{4}$. Lao has five demonstrative elements, none of which may appear independently as agent or undergoer noun phrases. Only two- $n i i^{4}$ and $n a n^{4}$ - are genuine demonstrative determiners, since only these two can generally be used as nominal modifiers in simple noun phrases like 'this book'. This puts $n i i^{4}$ and $n a n^{4}$ in paradigmatic opposition to each other only. The remaining three are demonstrative adverbs ( han $^{5}$ 'there', phii 'here', and phun $^{4}$ 'yonder'). The two nominal-modifying demonstrative determiners $n i i^{4}$ and $n a n^{4}$ have different degrees of semantic specificity. $\mathrm{Nii}^{4}$ is the more semantically general member of the pair,

\footnotetext{
${ }^{13}$ The perimeters of these areas are FELT by people, and the monitoring of such perimeters is seldom if ever explicit. Sensitivity to these socially meaningful spaces is suggestive of the inexplicit, unarticulated yet 'cultivated disposition, inscribed in the body schema' described by Bourdieu (1977:15; cf. Hanks 1990). It remains unclear what is the COGNITIVE status of people's ongoing monitoring of engagement and closure in interactional space.
} 
encoding nothing more than a basic primitive demonstrative meaning (paraphrasable as 'this (one)', 'the (one) that is mutually salient enough in this context for you to know which one I must mean', expressed here as DEM). $\mathrm{Nan}^{4}$ is the semantically more specific member of the pair, encoding the same basic demonstrative meaning PLUs the specification that the referent is something 'not here'.

(1) a. $n i i^{4}=$ DEM

b. $n a n^{4}=$ DEM NOT HERE

These two are paradigmatically related to each other and form an entailment scale (Levinson 2000:79), whereby use of the semantically more general of the two can implicate (but cannot entail) the converse of the semantically more specific of the two. The semantically more specific $\operatorname{nan}^{4}$ encodes that the referent is (something) located in a region that is 'not here', while the semantically more general $n i i^{4}$ (given that $n a n^{4}$ is an option in the same grammatical environment) can implicate, but cannot entail, the converse of $\operatorname{nan}^{4}$, namely that the referent is 'here'.

This kind of analysis of multi-term demonstrative systems - that is, as consisting of one semantically general term that may be enriched by inference in opposition to other, semantically more specific, terms - was prefigured by Halliday and Hasan (1976:59) and by Wierzbicka (1980:27), and has also been explored in recent collaborative research by the Space Group of the Max Planck Institute for Psycholinguistics, Nijmegen (Wilkins 1999, van Geenhoven \& Warner 1999:58). The idea of characterizing the distinctive semantics of a marked distal form as 'not here' was earlier suggested by Wierzbicka (1980:27). My reason for pursuing 'not here' as the operative semantic distinction in the Lao case is that it allows preservation of a discrete intensional semantic value invariant across all uses, while remaining consistent with wide variation in context-specific extensional value, due to often highly complex external factors. While it may be tempting to suggest that $n i i^{4}$ entails 'here', I pursue the claim that it does not, for three reasons. First, it is not necessary to do so in order to account for the data, and thus is favored by Ockham's principle of simplicity. Second, refraining from attributing any spatial information to the intension of $n i i^{4}$ allows a monosemy analysis of $n i i^{4}$ such that its endophoric uses (not explored in this article) are handled under the same single meaning as its exophoric uses. This is again a choice favored by Ockham's principle of simplicity. Third, according to informants' judgments, nii ${ }^{4}$ is always a conceivable possibility in contexts where $\mathrm{nan}^{4}$ has been used but the reverse is not true. This is evidence that the two forms are not symmetrical in semantic content, and more specifically, that $n i i^{4}$ is semantically more general than $n a n^{4}$.

I turn now to examples that provide evidence for the claims being made here, namely that (a) of the two Lao demonstrative determiners, $n i i^{4}$ is semantically general and nan $^{4}$ is semantically more specific; (b) the added semantic content of an $^{4}$ specifies that the referent is something 'not here'; (c) neither $n i i^{4}$ nor $n a n^{4}$ encode semantic distinctions of 'distance'; and (d) the choice of demonstrative determiner is made with reference to the perimeter of the speaker's here-space as conceived in the interlocutors' common ground. These conceived perimeters are emergent from factors of the interaction, including active engagement areas, physical features of the interactional space, and assumptions about addressees' access to relevant information for inference.

5. Uses of SEMANTICALly MORE SPECIFIC $\mathrm{nan}^{4}$. The message common to all exophoric uses of $n a n^{4}$ is that the referent is something 'not here'. This section describes a range of circumstances that can lead a speaker to decide that sending this message, rather than simply using the semantically general demonstrative $n i i^{4}$, will be more likely 


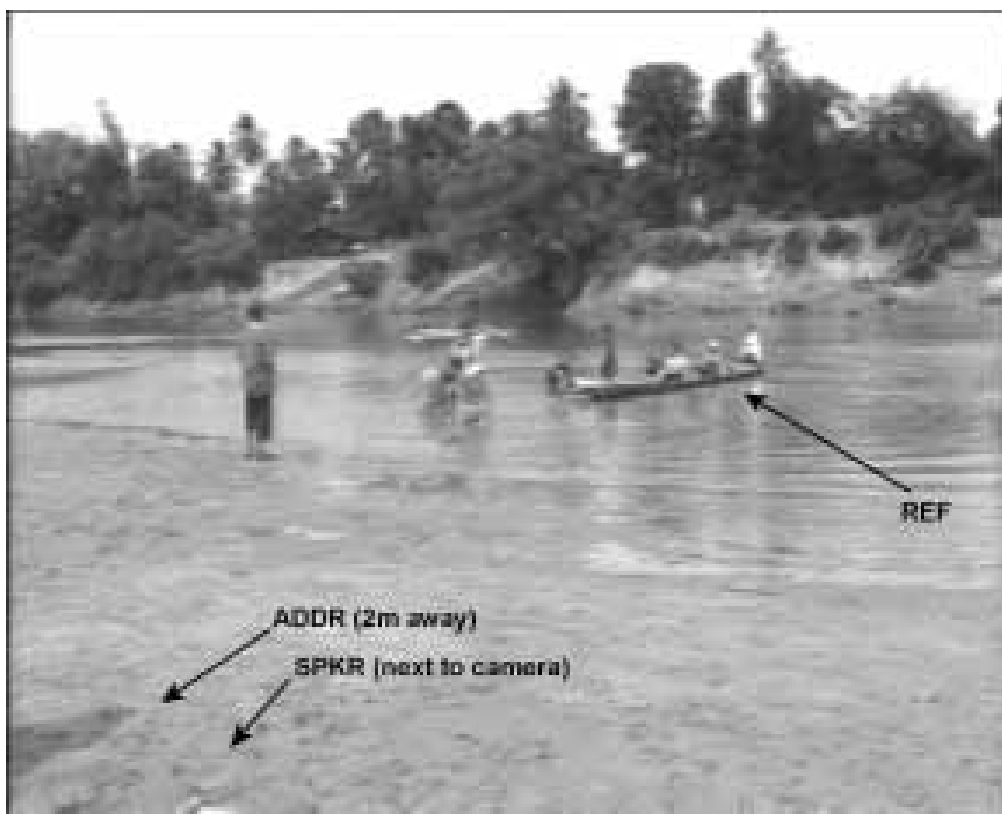

FIGURE 1 . 'There's only children in $\operatorname{nan}^{4}$ boat.'

to result in a convergent solution by speaker and addressee to the coordination problem at hand. Following are examples of two situations in which a referent may come to be conceived of as 'not here'. In the first, the speaker may have a saliently bordered herespace, where the referent is plainly not in it. In the second, the addressee may have a salient here-space perimeter, where the referent is plainly in it AND the speaker does not share here-space with the addressee. This entails that the referent is, for the speaker, 'not here'.

5.1. SituAtion: SPEAKER HAS SALIENT HERE-SPACE PERIMETER, REFERENT IS NOT IN IT. CASE 1: Speaker's here-space perimeter is defined by engagement with the addressee; referent is not in it.

One situation that leads to construal of a referent as being 'not here' is when it is outside the speaker's here-space perimeter due to a salient here-space closure arising from an engagement involving both speaker and addressee $(=(\mathrm{bi})$ in Table 1$) .{ }^{14}$

(2)

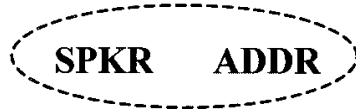

REF

In Figure 1, a number of children have gotten into a boat and are about to cross the river. The boat is about thirty meters from the camera. Immediately to the left of the camera (1-2 meters away) are two people engaged in casual conversation. One speaker (a woman) notices the children in the boat getting ready to cross, and remarks 'There's only children in nan $^{4}$ boat'. ${ }^{15}$

\footnotetext{
${ }^{14}$ The here-space perimeter is represented here, and below, as a dotted line circle or ellipse. The abbreviations Spkr, Ref, and Addr stand for 'speaker', 'referent', and 'addressee', respectively.

${ }^{15}$ To save space, I do not supply the full utterances in Lao. What is relevant to this discussion is the basic meaning of the utterance as a whole, and whether the speaker selects $n i i^{4}$ or $n a n^{4}$.
} 


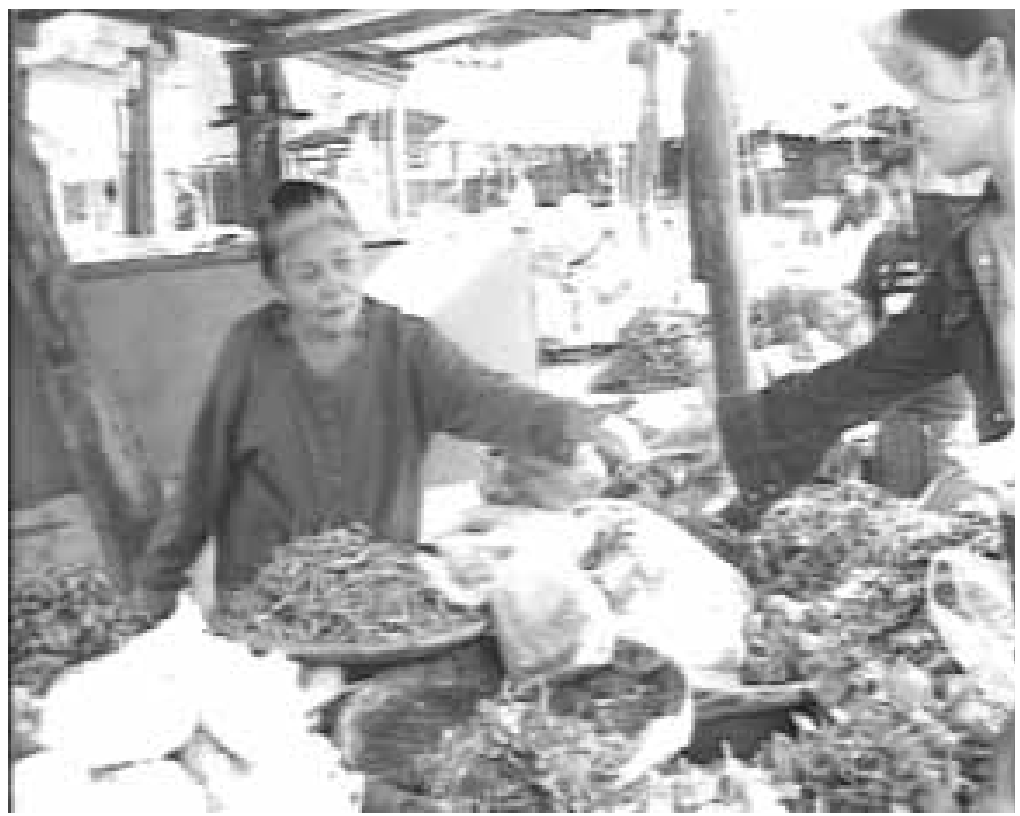

FIGURE 2a. Customer (right) and merchant (left) with joint attention and coordinated manual action of exchanging goods for cash.

The speaker's use of $\operatorname{nan}^{4}$ to refer to the boat signals that the boat is 'not here' from her point of view at that moment. Her current dominant engagement is a conversation that does not extend to or involve the people visible in Fig. 1, who are out of earshot and engaged in the riverside action. It is clear to the interlocutors that the referent is in a place well outside of the here-space defined by their current 'local' conversation. Thus, the speaker can assume that her interlocutor will also understand the boat as being in a place 'not here', at the relevant moment. ${ }^{16}$

Figure 2 shows a customer and a merchant in the middle of a sale. In Fig. 2a, they together create a tight engagement area with their joint attention on physically coordinating an exchange of produce for cash.

In Fig. 2b, as the merchant has now taken the money, and the two withdraw, the merchant breaks out of the established engagement space by turning to her right and pointing, with gaze and outstretched index finger, to some tomatoes, asking ' $\mathrm{Nan}^{4}$ ones, won't you put some in?'.

The merchant has been told what the customer is planning to cook, knows that the recipe requires tomatoes, and knows that the customer hasn't purchased tomatoes yet. At the moment that she wants to draw the addressee's attention to the tomatoes, a common here-space is already mutually salient to the two interlocutors (the space defined by the tight engagement area arising from their joint attention and manual engagement in synchronizing the cash exchange illustrated in Fig. 2a). The tomatoes are out of the salient perimeter of that here-space. Thus, the speaker uses the demonstrative $n a n^{4}$ in referring to them, - specifying that they are 'not here'. The status of the referent as 'not here' is determined by facts about how perimeters of interactional space

\footnotetext{
${ }^{16}$ An example from moments later in this same scene, discussed in $\$ 6.1$ (cf. Fig. 8), discusses a very different construal, by a different speaker, of the same physical speech setting.
} 


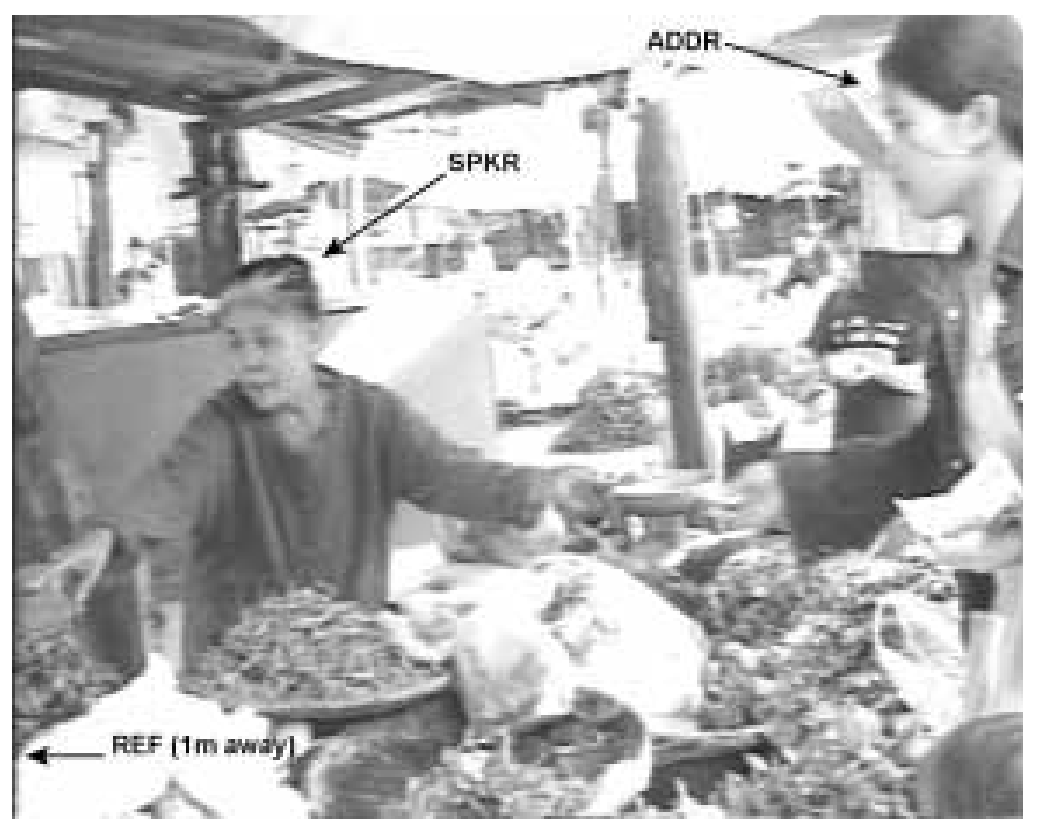

FIGURE 2b. 'Nan ${ }^{4}$ ones, won't you put some in?'

acquire mutually salient status for interlocutors. The perimeter of 'here' at this moment cannot be determined with reference to simple spatial geometry alone.

CASE 2: Speaker's here-space perimeter defined by tight solo-engagement, excluding addressee; referent is not in it.

A referent may be construed as 'not here' when a salient perimeter of the speaker's here-space arises from the speaker's solo-engagement, AND the referent is beyond that perimeter. This case is like the previous in that the referent is out of the speaker's herespace perimeter, but it is unlike the previous in that the here-spaces of the speaker and addressee do not overlap ( $=$ (bii) in Table 1$)$.

(3)

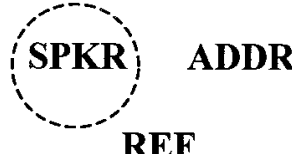

In Figure 3, both speaker (merchant, second from left) and addressee (customer, far left) are very close to the referent. Fig. 3a shows the merchant (second from left) standing next to the customer (far left) at the corner of her market table. However, the merchant is engaged in a verbal exchange with the man at the back of the stall (who has not participated in any interaction involving the customer) and is also 'solo-engaged' in the manual task of wrapping up the customer's purchase of meat. ${ }^{17}$

At this point, the customer asks the price of a piece of meat on the corner of the table immediately between her and the merchant. The merchant turns to look down at

\footnotetext{
${ }^{17}$ This example also has an element in common with 2 above, in that the here-space of the speaker, which does not contain the referent, is partly determined by the speaker's interaction with another person. In this case, however, that person is not the addressee.
} 


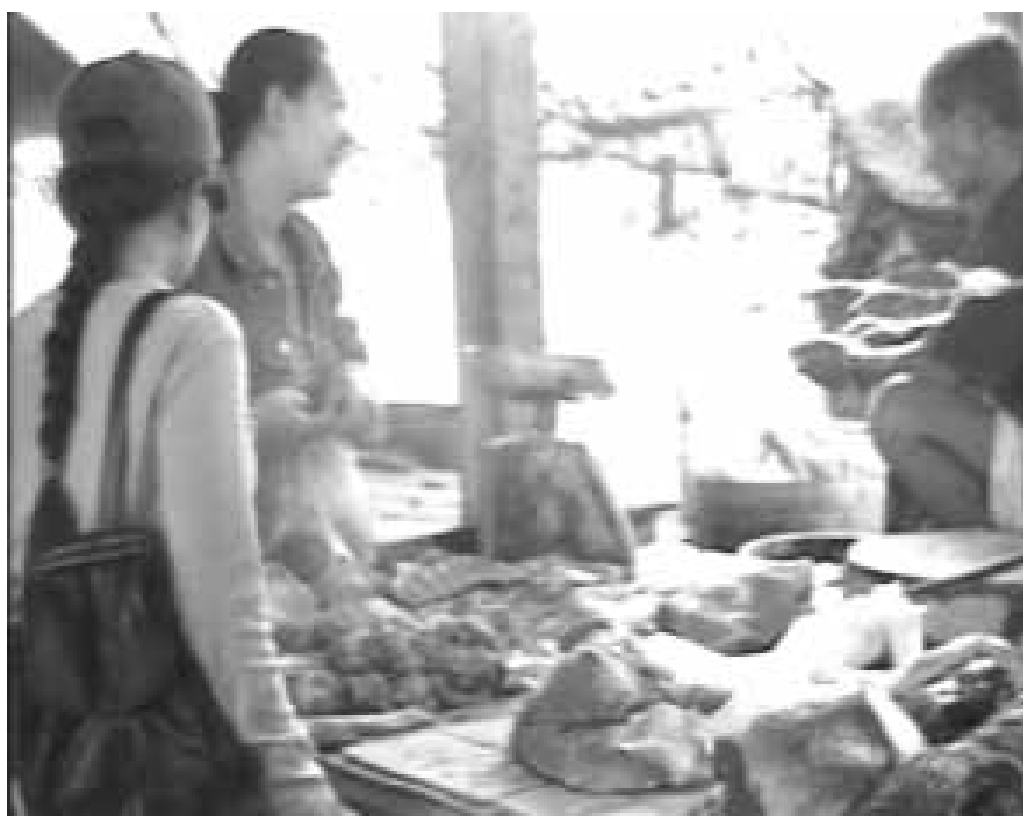

FIGURE 3a. Merchant (second from left) in an engagement area whose perimeter excludes customer (far left).

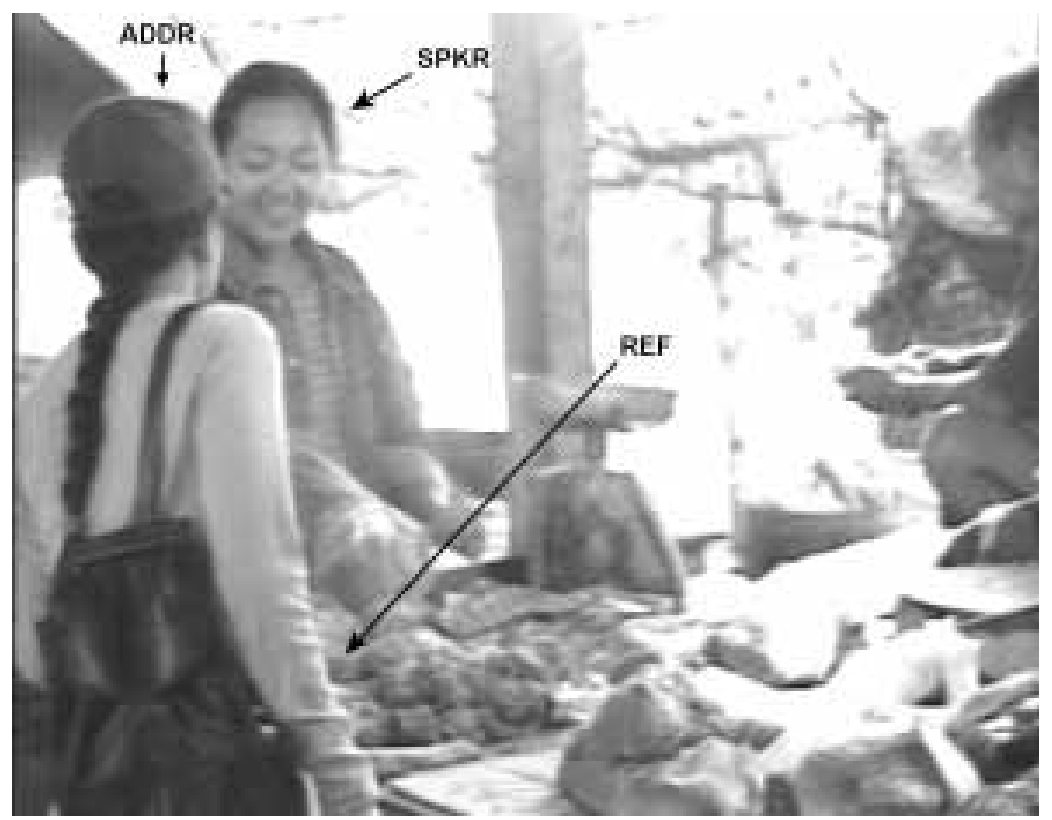

FIGURE 3b. 'Nan 4 one is 16 per kilo.' 
the meat in question, still engaged in wrapping the previous purchase, and answers 'Nan ${ }^{4}$ one is 16 per kilo'. ${ }^{18}$

This is a good example of a referent physically very close to the speaker (literally, within arm's reach) being referred to by a so-called distal demonstrative. I checked with consultants about which demonstrative would be expected, giving only information about the spatial layout of speaker, referent, and addressee, and no information about engagements or other interactional dynamics. There was an overwhelming preference for $n i i^{4}$ in this case. Great proximity of the referent to the speaker suggests default inclusion in here-space, but this was overridden in the example described here by a salient interactionally established here-space perimeter very close to the speaker. How could a model of demonstratives as semantically encoding 'distance' deal with the paradox of a distal demonstrative being used in an indisputably proximal context? The example shows that we cannot appeal to objectively measurable distinctions of physical distance, but must acknowledge that what determines the choice here is a conceived perimeter in the space, again not as mere space but as INTERACTIONAL SPACE.

CASE 3: Closure of speaker's here-space perimeter determined by physical properties of the interactional space; referent is not in it.

While here-spaces are essentially conceptual entities established by people's INTERPRETATION of space, physical properties of a situational setting can have a strong effect on such interpretations. Physical entities like walls, doorways, conventional 'wallprojecting' items like chair backs, and other obstacles are conventionally acknowledged barriers that speakers and addressees can mutually recognize (Goffman 1963, Scheflen 1976). Such physical properties are common ground for interlocutors based on perceptual evidence (Clark et al. 1983:247, Clark 1996:112); that is, they are common ground by virtue of being plain for both to see. Conceived barriers of this kind can override other features of common ground as determinants of here-space perimeters.

I am arguing that a speaker's physical and/or perceptual access to a referent can be a factor in selection of one of the two Lao demonstratives, but I am NOT saying that 'visibility' or 'access' are encoded in their semantics. The speaker's lack of access to the referent is what causes it to be conceived of as 'not here', and it is the conception of the referent as 'not here', rather than the 'lack of access', that is encoded in the Lao demonstrative $n a n^{4}$. The descriptive linguist thus has reason to show caution before claiming that a factor such as 'visibility' is SEMANTICALLY ENCODED in a demonstrative system (see e.g. Diessel 1999:40-42). This is NOT to deny the possibility that visibility might be encoded in a demonstrative system, but to caution care in distinguishing whether a feature such as visibility is part of encoded meaning or is a contextual factor that forces the choice of another, more general semantic meaning. ${ }^{19}$ I describe below (\$7) a case in which the ADDRESSEE's access to the situation can also, via quite a different mechanism, determine a speaker's choice of demonstrative.

I now offer two examples in which a physical barrier in the interactional space contributes to recognition of a here-space perimeter (and, accordingly, selection of an appropriate demonstrative).

\footnotetext{
${ }^{18}$ The currency unit is the Kip (approximately $8500=$ USD1 at the time of recording). References to prices 16 and 17 are in thousands.

${ }^{19}$ The point made here may also shed light on how a demonstrative term with semantic encoding for visibility of a referent might grammaticalize.
} 


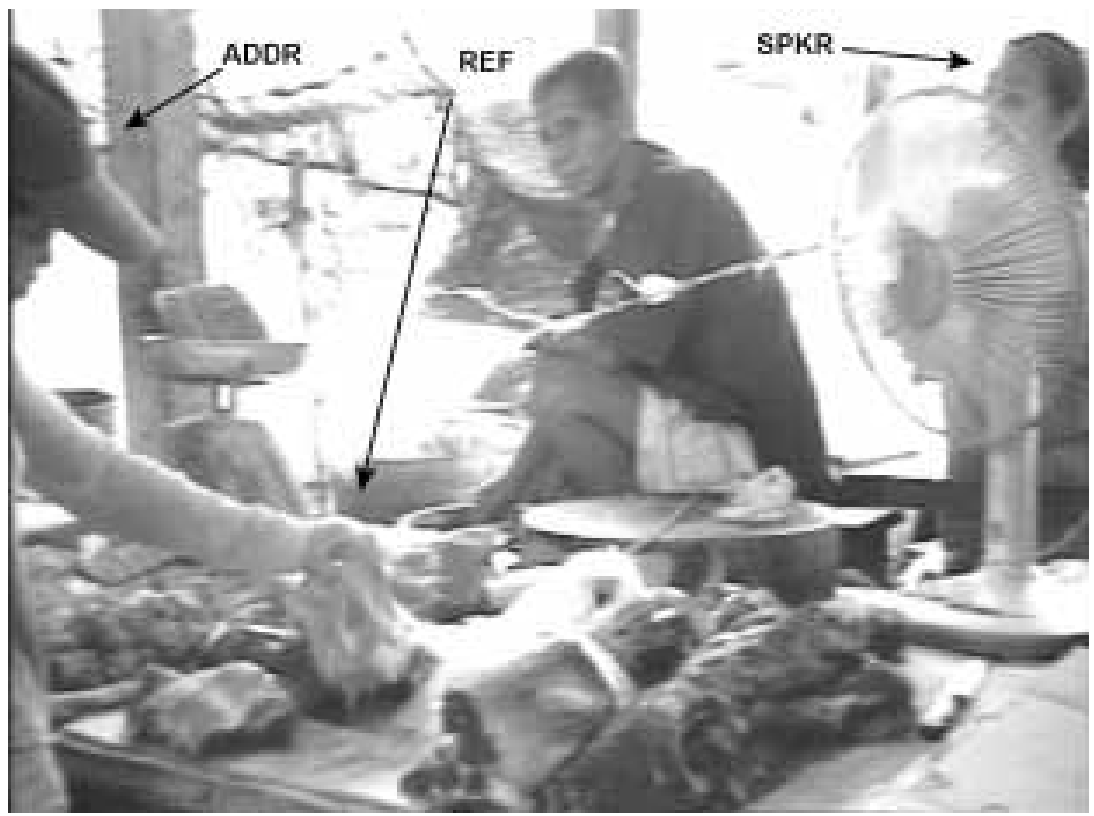

Figure 4. 'Nan ${ }^{4}$ one is 17 per kilo.'

In Figure 4, a merchant (to far right) is behind her market table, obscured by an electric fan on one side of the table. There is also a man sitting behind the table (on another table) to the other side, and a plastic bag on a string attached to the fan (to deter flies and wasps) hovering in the air and blocking the view across the table (left center). Each of these factors, as well as the vacant space between the merchant and the table itself (since she is standing away from it), form a perceptually salient physical barrier in the common ground of the interlocutors and is thus naturally construed as a here-space perimeter. Further, the merchant is in a solo-engagement, wrapping the customer's purchase. The customer asks the price of a piece of meat on the table (using $n i i^{4}$, for reasons outlined in $\S 6$ ), and the merchant replies, from her position behind the electric fan, ' $\mathrm{Nan}^{4}$ one is 17 per kilo'.

The merchant's choice to encode the referent as 'not here' is due to a here-space perimeter that has arisen partly from the presence of physical barriers in the interactional space and partly from her own self-enclosing solo-engagement at the moment of speech.

I have described to consultants the spatial geometry of speaker, addressee, and referent in this example, and they are unanimous that the speaker could have used proximal $n i i^{4}$. Indeed, I have often observed uses of $n i i^{4}$ in situations of similar spatial layout. But given the interactional dynamics in this real context, the speaker had good reason to use the more semantically specific form $\mathrm{nan}^{4}$. Once again, information about physical distances between interlocutors and a referent alone cannot account for the distribution of demonstrative selection.

The three parts of Figure 5 show two women-call them the hat woman and the older woman-engaged in a discussion about how to operate a second-hand washing machine that the older woman has just acquired. The machine was previously at the house of the hat woman, and the older woman is asking the hat woman details about how to operate it. Fig. 5a shows the two women's joint attention on the water inlet of the washing machine, as the older woman points at it with her index finger, asking 


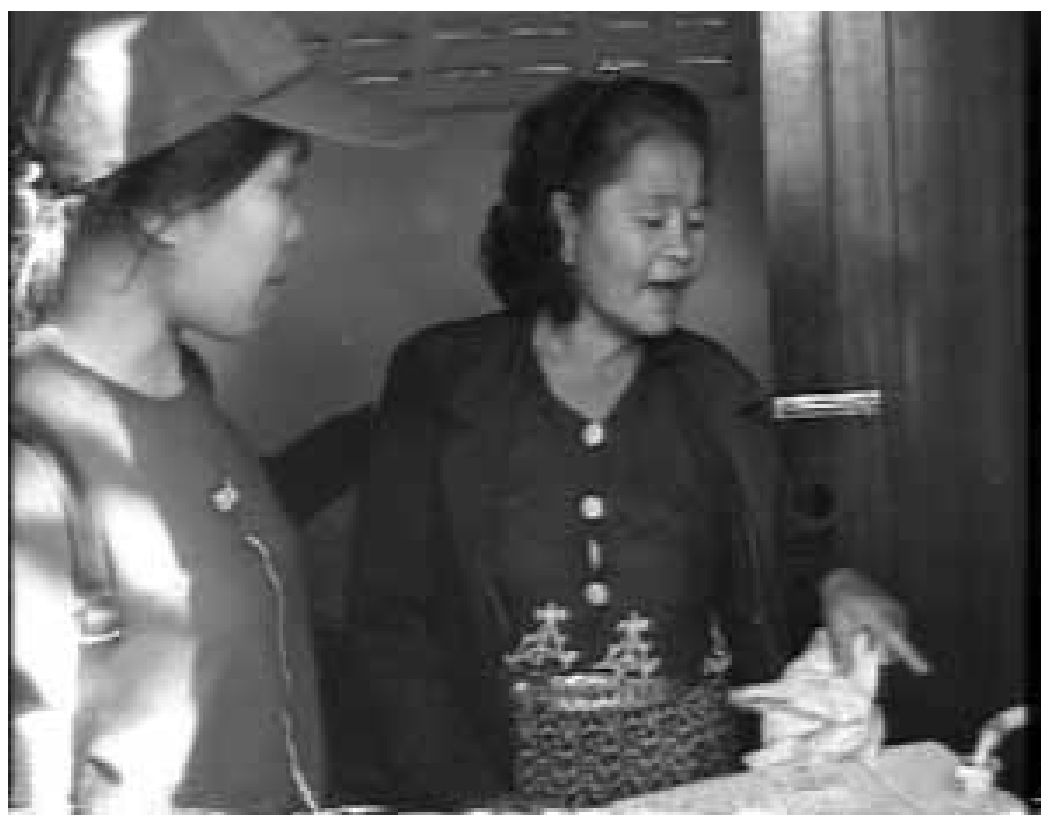

Figure 5a. Joint attention on water inlet to washing machine.

'And what did you do about water?' (referring to the arrangement connecting the water inlet to a water supply).

Up to this moment, the women have created a tight engagement area encompassing the two of them and the washing machine, where their joint attention has been focused for some time. They have been physically huddled over the washing machine. Then, as illustrated in Fig. 5b, the hat woman looks up and out of the current engagement area, to a tap on the wall, which is connected to the washing machine's inlet hose. She points at the tap with gaze and outstretched index finger, saying 'Keep (it) on the whole time, nan $^{4}$ thing'.

Although the referent is less than 2 meters away (as shown in Fig. 5c), there is nonetheless a significant physical barrier - the washing machine together with the body of the older woman-between it and the speaker, and the presence of this barrier is perceptually salient to both speaker and addressee. The referent is well and truly out of the speaker's physical reach. ${ }^{20}$

This example demonstrates how a barrier to physical access can contribute to establishment of a relevant here-space perimeter. There is also a contribution from the rather restricted perimeter of the engagement area the speaker had already set up with the older woman (illustrated in Fig. 5a). Note that this is maintained by the older woman's visual attention on the speaker and not on the referent in Fig. $5 \mathrm{~b}$.

5.2. SituAtion: AdDRESSEe has SAliENT HeRE-SPACE PERIMETER, REFERENT IS IN IT, SPEAKER IS NOT. Suppose an ADDRESSEE has a saliently bounded here-space perimeter, arising from his or her engagement with someone other than the speaker or with some

\footnotetext{
${ }^{20}$ Note that the speaker does not have access to the referent via the right side of the washing machine (the side closest to the camera). The video recording is taken from outside a window looking in, and the washing machine is against a wall.
} 


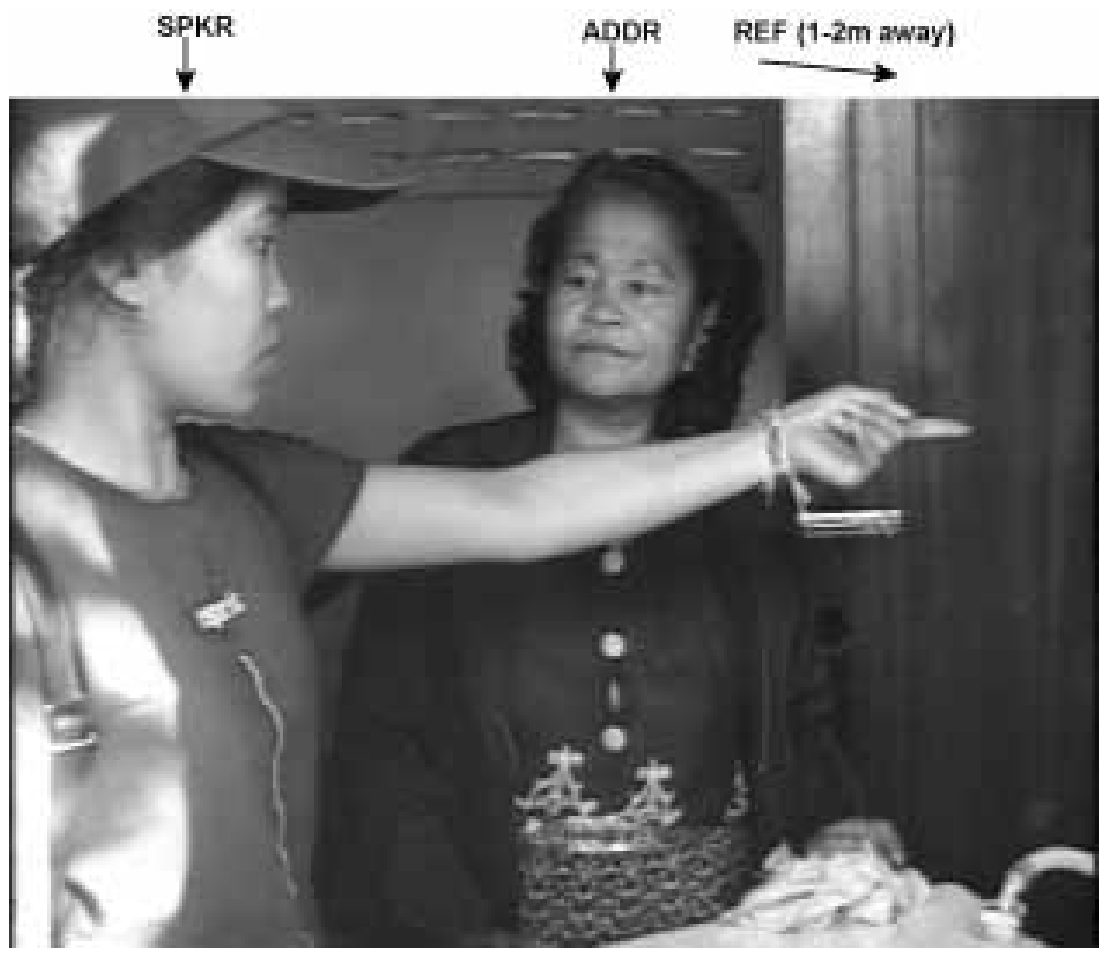

Figure 5 b. 'Keep it on the whole time, nan $^{4}$ thing.'

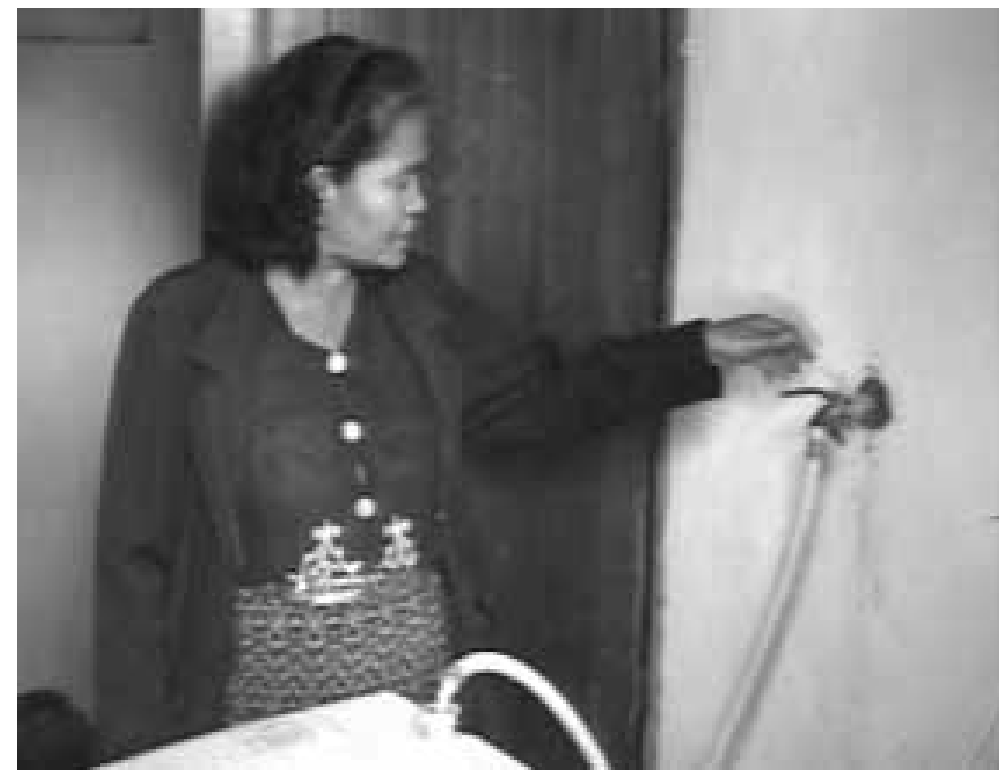

FiguRE 5c. Referent of deictic gesture and demonstrative in Fig. 5b: Tap connection for water inlet to washing machine. 


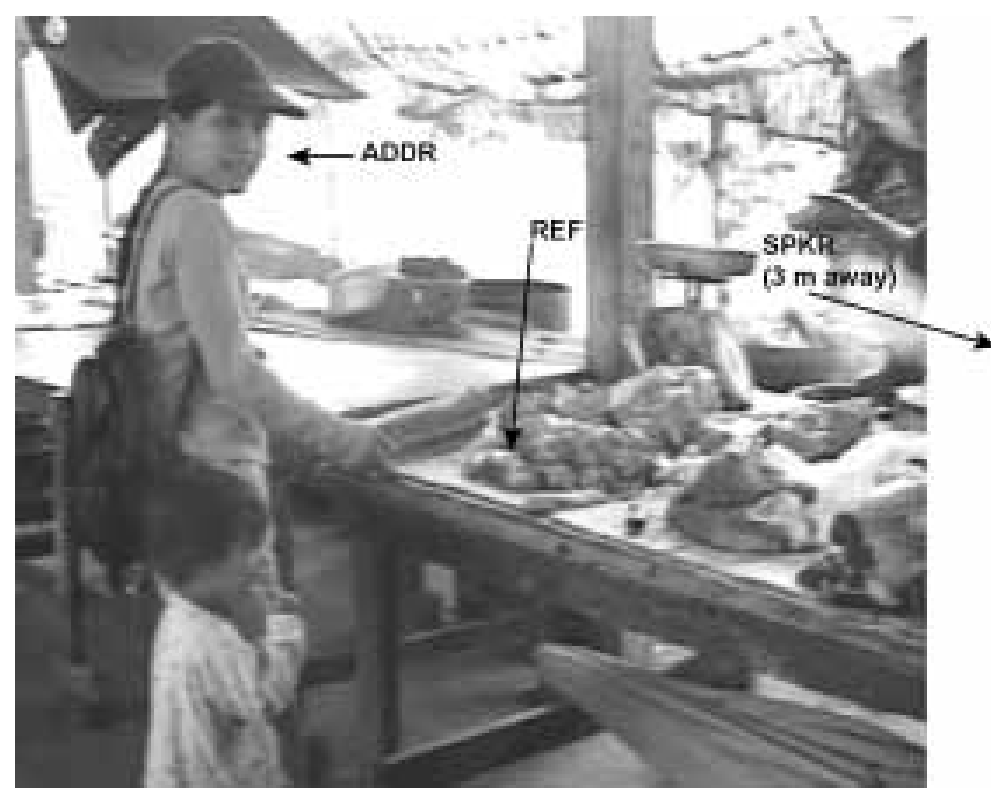

FIGURE 6. 'Nan ${ }^{4}$ insects!' (Referents-wasps—at table's edge in front of hat woman's hand; speaker behind camera to right.)

object. If the referent is in that space (especially if it is the focus of the addressee's attentional and/or manual engagement), and if the speaker is outside that space, then the referent must be 'not here' for the speaker (regardless of the positively defined extent of the speaker's here-space). The speaker will thus use $\operatorname{nan}^{4}$ to encode the idea that the referent is 'not here'. ${ }^{21}$ Schematically:

(4)

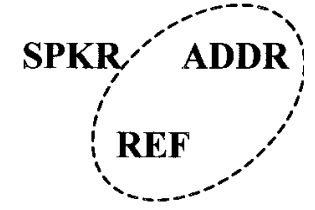

Figure 6 shows a customer (the hat woman), accompanied by a child, standing at a market table. The woman is in the middle of a fairly involved purchase of a number of different types and quantities of meat (visible on the table), and there is an established active engagement area for her that includes the array of meats on the table and the merchant, who is on the other side of the table (out of camera frame, to right). There are a number of other people standing around, conversing and eating together, in front of the adjacent market table (away approximately three meters to the right of the hat

\footnotetext{
${ }^{21}$ Martina Faller (personal communication) has expressed some disquiet with this analysis, suggesting that it is problematic for the speaker's here-space not to be positively defined, thus begging the question of how the location of 'not here' can be computed. Let me clarify the logic of what I am claiming: premise 1 -the referent is in the here-space of the addressee; premise 2-the here-space of the speaker does not overlap with that of the addressee; conclusion — the referent must be 'not here' for the speaker. I am suggesting that as long as the ADDRESSEE's here-space perimeter is saliently and clearly defined AND there are clear and salient reasons for the speaker and addressee to be regarded as NOT SHARING respective here-spaces, then there is no need to know the extension of the speaker's here-space in order to calculate the location/identity of the referent on the basis of a speaker's 'not here' specification.
} 
woman and the child in Fig. 6), and these people form their own, quite separate, interactional closure. One man in the group of people to the right (out of camera frame) notices that the child in Fig. 6 is trying to play with some wasps that are buzzing around the meat on the table, and warns the hat woman, implying that she should intervene. Fig. 6 shows her backing away from the table, looking at him as he speaks. He uses the demonstrative $n a n^{4}$ in referring to the wasps (i.e. as mèèng $g^{2} q a n^{0}-n a n^{4}$ [insect clf-nan ${ }^{4}$ ] ' $n a n^{4}$ insects'), specifying that they are 'not here'.

This use of $n a n^{4}$ accords best with the likely shared assumption about perimeters of the speaker's and addressee's respective here-spaces, and the location of the referent with respect to those spaces. It is plain to both speaker and addressee that the referents - wasps - are firmly in the addressee's here-space, the perimeter of which coincides with the interactional closure of the purchase-at-market-table scenario. The man standing away to the right (out of shot) has up to this point had no interaction with the addressee, and thus is not part of the engagement which had established the addressee's here-space closure. It is as if out of politeness that he should use $\operatorname{nan}^{4}$ here, to signal explicitly that he does not PRESUME that he shares a single here-space with his addressee (a stranger). Further, he is within an engagement area of his own, in an inward-oriented circular formation he has created with his conversational interlocutors (Kendon 1977: ch. 5). Thus, the referent is for the speaker 'not here', and this is encoded by his use of $\mathrm{nan}^{4}$. This solution is sensitive to shared assumptions (and likely counterassumptions) about common ground in the context, since the active here-space closures are mutually salient to all concerned. The choice could not be explained without taking the interactional context into account (e.g. by appealing to a distinction of physical distance).

I asked consultants to judge which demonstrative would be appropriate, describing only the physical spacing of speaker, referent, and addressee in this example and suppressing information about the interactional context. As in other examples discussed in this article, consultants responded that the speaker could have used either $n i i^{4}$ or $n a n^{4}$ for that referent. But in the real situation the speaker chose $n a n^{4}$. Given the richer interactional context, consultants agreed that $n i i^{4}$ would have been very odd, and probably confusing. Once again, interactional dynamics are crucial in selection of demonstratives. A method of analyzing demonstrative distinctions which cannot take these factors into account is therefore too blunt a tool.

Figure 7 shows the hat woman to the left, involved in the purchase of vegetables at a stall attended by an older woman ('older merchant', center) and a younger woman ('younger merchant', to right). The hat woman and the older merchant are currently in a tight engagement area, created by their joint attention on selecting a number of different vegetables at the leftmost end of the market table where they are standing. They are physically oriented to each other, both bending over, jointly attending to the produce on the table between them, forming a closure that excludes the younger merchant, who is standing well back and observing. There is an interactional (and also visual) GRAVITY pulling the two women together to the exclusion of the third, and since this is perceptually apparent to each of the three women in this scene, it is common ground between them.

The hat woman asks the price of some tomatoes (using $n i i^{4}$, for reasons outlined in §6) that are in the center of the tight engagement area she maintains with the older merchant. It is the younger merchant behind who responds, saying ' $\mathrm{Nan}^{4}$ ones are 2500 (per kilo)'.

The addressee and referent are together in a tightly established here-space whose perimeter does NOT include the speaker (the younger merchant, to right). The speaker's 


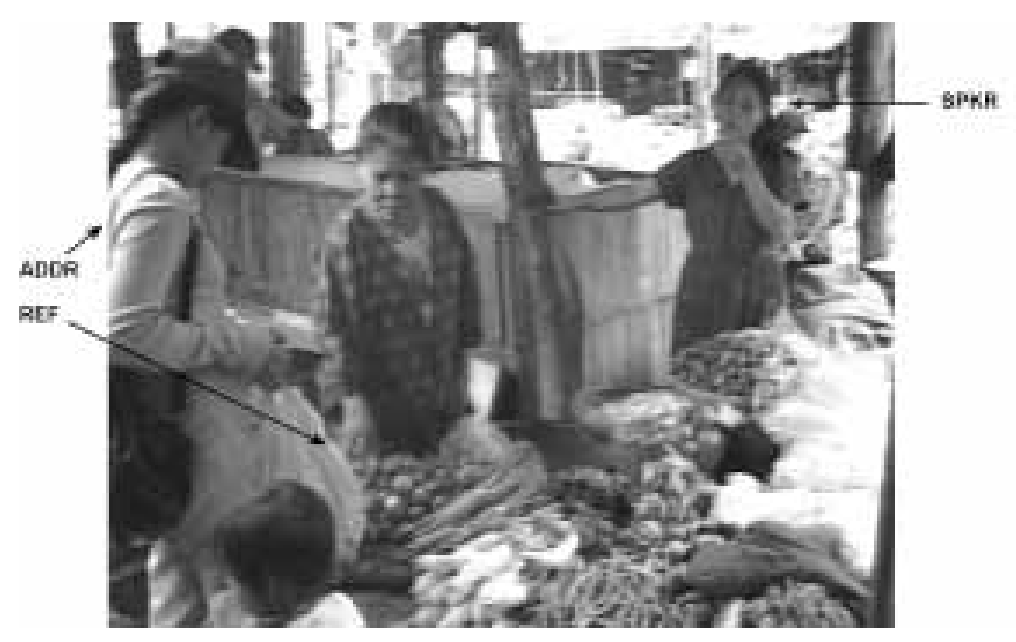

FiguRE 7. 'Nan ${ }^{4}$ ones are 2500.'

use of $n a n^{4}$, asserting that the referent is something 'not here', indexes her nonsharing of that here-space (where the referent is located). Recall the logic here: premise 1 - the referent is in the addressee's here-space; premise 2-the speaker does not share the addressee's here-space; conclusion - the referent cannot be in the speaker's here-space (regardless of the positively defined extension of that space).

As mentioned in discussing the previous example, the mere spatial layout of speaker, addressee, and referent in this example is not sufficient to get consultants to agree that one or another demonstrative is obligatory or especially preferred. In this case, the fact that the addressee is already engaged in interaction with a third person (who is neither speaker nor addressee) is crucial in the speaker's selection between the two available demonstrative determiners. It is only when we understand the complex dynamics of the interaction in real time that the interactional logic of the appropriate choice of demonstrative becomes clear.

5.3. Summary. I have shown in this section that nan $^{4}$ encodes an intensional meaning consisting of DEM (which specifies that the reference of what it marks should be recoverable by the addressee with reference to salience in common ground) plus a specification of the spatial location of the referent, namely that it is 'not here'. This is revealed by its use in two types of situations. In the first type, the perimeter of the speaker's herespace is salient in the interaction AND the referent is not within that perimeter. This situation can arise in a number of ways, depending on the factors that determine a publicly salient closure of the speaker's here-space (including perceived spatial closure created by interactional engagement, and more tangible spatial closure created by distance and/or physical barriers). In the second situation, the perimeter of the ADDRESSEE's here-space is salient in the interaction AND the referent is within that perimeter AND the speaker's here-space does not overlap with that of the addressee.

6. USES OF SEMANTICALLY MORE GENERAL DEMONSTRATIVE $n i i^{4}$. What all uses of $n i i^{4}$ have in common is that the speaker is NOT saying that the referent is something "not here'. Given that Lao speakers have one other choice of demonstrative determiner $\left(n a n^{4}\right)$, which encodes that the referent is something 'not here', the use of $n i i^{4}$ often implies (but never entails) that the referent is something 'here'. In other words, $n i i^{4}$ 
and $\mathrm{nan}^{4}$ form an entailment scale (Levinson 2000:79), with $n a n^{4}$ the 'strong' member of the pair. While $n a n^{4}$ is genuinely specified for 'awayness' (a locational specification that must not be confused with marking for 'distance'), the status of $n i i^{4}$ as proximal arises entirely by inference due to its relation in the system to the more semantically specific alternative. $\mathrm{Nan}^{4}$ and $n \mathrm{ni}^{4}$ are not equivalent in semantic complexity, and their status as distal and proximal, respectively, is qualitatively distinct. $\mathrm{Nan}^{4}$ has a semantic specification for 'WHERE the referent is', while $n i i^{4}$ does not. Consider now two main situations in which $n i i^{4}$ is used in spontaneous interaction.

6.1. SituAtion: NO HERE-SPACE PERIMETER IS PARTICULARLy SALIENT. In the following examples, the speaker's engagement area is large and diffuse, such that there is no particular contextually salient perimeter of 'here' within the local interactional space. As a result, it becomes inappropriate to specify as 'not here' even a referent quite far from the speaker. Such cases support the view that $n i i^{4}$ is nonspecified with respect to place (or 'hereness'). The fact that no particular here-space perimeter is mutually apparent to interlocutors means that an explicit specification of the referent's location with reference to 'here' (or 'not here') is information the addressee cannot use. Speakers are presumed by addressees to take addressees into account in formulating utterances meant to be interpreted by those addressees (Sacks \& Schegloff 1979, Clark 1996). If there is a mutually obvious here-space perimeter in an interaction, then an addressee can expect a speaker to refer to it in inviting a certain interpretation. But when no such perimeter is salient in the common ground, then a speaker cannot expect explicit reference to the notion of a here-space perimeter to be of any use in interpreting the speaker's utterance. Instead, the addressee would struggle to comprehend the relevance of such a specification. I offer two examples.

In Figure 8, a man is descending a river bank, calling out to children in a boat, who are setting off to cross the river. The shot is taken from the same location as Fig. 1, swiveled about 120 degrees to the left, only seconds after the moment captured in

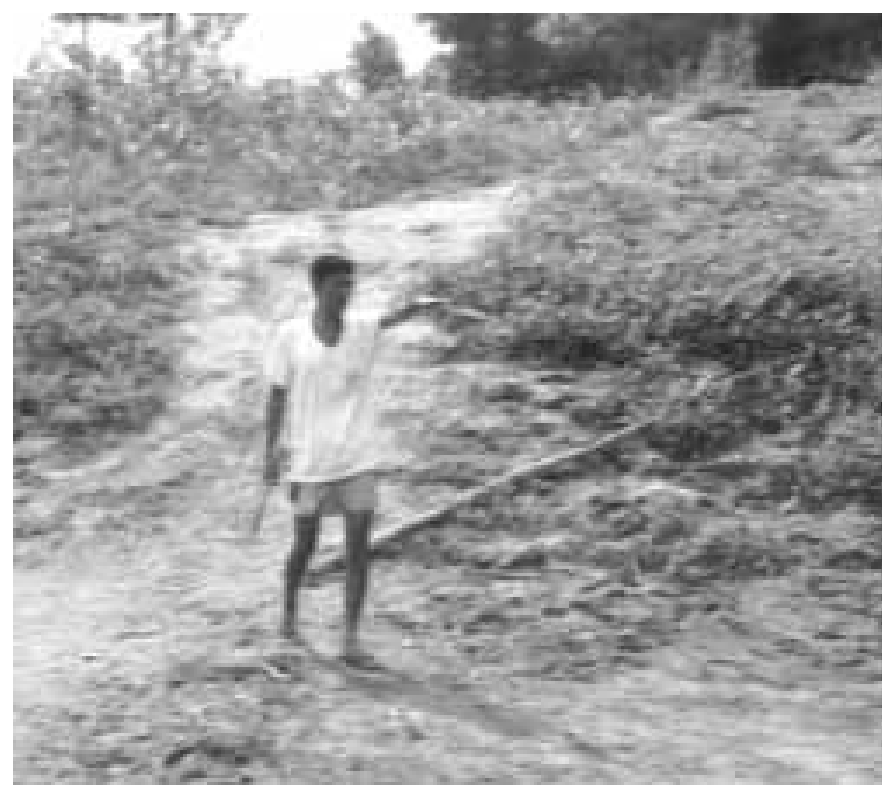

FIGURE 8 . ' $N i{ }^{4}$ boat landing!' 
Fig. 1. The speaker wants the children in the boat to cross the river and embark at a particular landing, and he calls out 'Nii ${ }^{4}$ boat-landing!, Cross to $n i i^{4}$ boat-landing!', index finger pointing with outstretched arm. The referent (namely the landing) is at least one hundred meters away. Fig. 1 shows both the boat and the landing (which can be seen as a bare patch on the river bank to the center left).

While the referent is surely far from the speaker, there is no particular reason why the speaker would want or need to specify that the landing he means is 'not here'. He is walking down the river bank alone, in no interactional or similar engagement that may create a salient locally closed here-space. He calls out to the children in the boat, who are over thirty meters away, and his voice is loud enough to be heard by everyone around. At this point, he is broadcasting his speech across a wide space, encompassing the whole open area of the river and its two banks, including all of those who can hear him as he shouts. There is no particularly salient here-space perimeter in the common ground, and he thus uses the semantically general demonstrative $n i i^{4}$ for this referent.

It is worthwhile to explicitly compare this example with Fig. 3b, above, in which the supposedly distal form $\mathrm{nan}^{4}$ was used with reference to something within hand's reach of the speaker. In the present example, the supposedly proximal form $n i i^{4}$ refers to something more than one hundred meters away from the speaker. Distance cannot be what distinguishes the meanings of these two demonstratives.

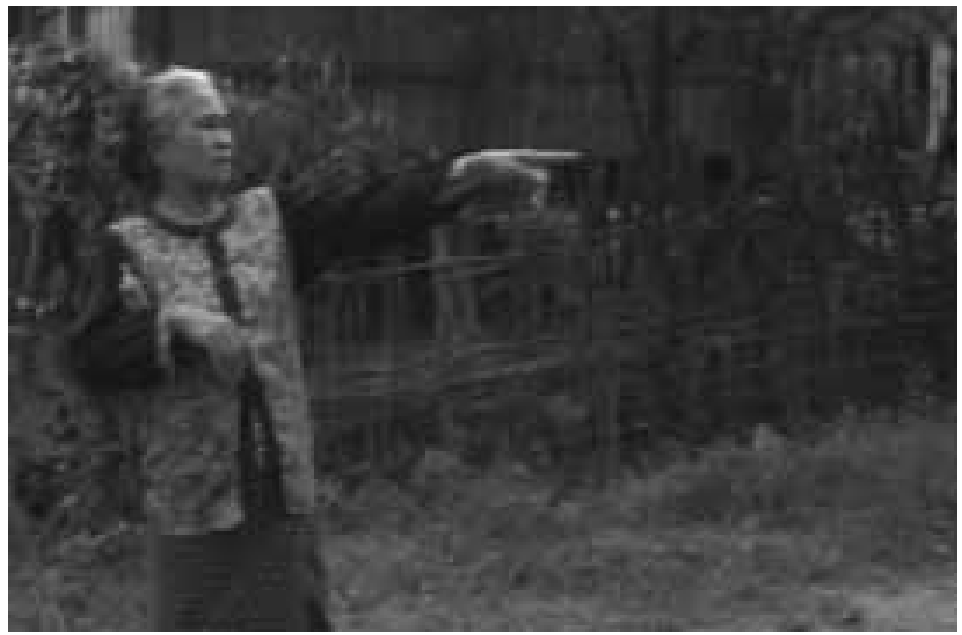

FiguRE 9a. ('Which one's pregnant?') 'Nii ${ }^{4}$ one.'

A similar situation pertains to Figure 9. Fig. 9a shows a woman, index finger pointing, arm outstretched. She is pointing across an irrigation ditch to one of a pair of buffaloes being led along by her brother-in-law (illustrated in Fig. 9b, below).

The woman is in the middle of a typically diffuse exchange of conversation with a number of people around the irrigation ditch and its banks, at varying distances. Such diffuse conversation is a common mode of interaction in the Lao village setting, partly due to the physical layout of Lao living areas (thin walls, windows without panes, doorways without doors, open-air verandas). People freely and comfortably converse with others who are not in the same spatial enclosure, and anyone within earshot of an interaction may normally assume involvement (unlike cultures such as that of, say, urban United States; Goffman 1963). The conversation just before the speaker's pointing gesture in Fig. 9a involved people some twenty meters to the woman's left, on the 
same side of the irrigation ditch, as well as the man leading the buffaloes along on the other side. One person had commented about the size of one of the buffaloes, which it turns out was pregnant. At this point the interactional engagement area is broad and diffuse, encompassing people (and buffaloes) on both sides of the ditch, with comments 'broadcast' more than directed at anyone in particular. In this larger interactional context there is no salient local closure around the speaker at the point when I (holding the camera) ask her 'Which is the pregnant one?'. Her response is to point, with index finger and gaze, saying ' $n i i^{4}$ one', as illustrated in Fig. 9a. Fig. 9b, from the same spot just seconds later (with the camera swiveled about 90 degrees to the right), shows that the referent, the furthest buffalo, is quite far from the speaker, at least twenty-five meters.

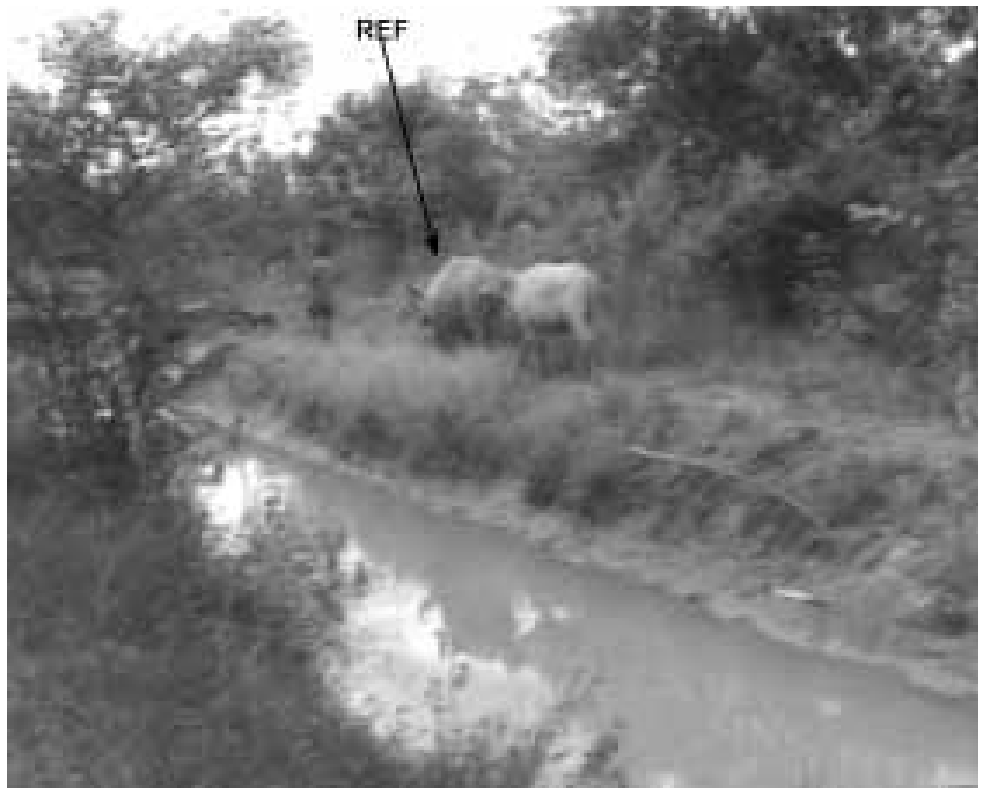

FIGURE $9 \mathrm{~b}$. Referent of $n i i^{4}$ in $9 \mathrm{a}$ is the buffalo in front.

The diffuse, broadcast nature of the interaction and the speaker's lack of any salient current engagement or attention at a more local level than the passing buffaloes and the scattered individuals within earshot meant that there was no impetus for her to encode the referent (the pregnant buffalo) as something 'not here'. She shared with her interlocutors no particularly salient idea of a here-space perimeter between her and the buffaloes, and so none was referred to.

6.2. SitUATION: SPEAKER HAS SALIENT HERE-SPACE PERIMETER, REFERENT IS IN IT. In many situations, there is a salient here-space perimeter around the speaker, and the referent is located within it (corresponding to (c) in Table 1). The speaker cannot expect any addressee to have assumed that the referent would be construed as 'not here', so the selection of $n a n^{4}$-encoding 'not here'-would be pragmatically confusing. This point makes reference to the principle of RECIPIENT DESIGN (Sacks \& Schegloff 1979), by which addressees can assume that messages have been formulated with them in mind. If a certain here-space perimeter is salient common ground in an interaction, then a speaker knows that an addressee can assume that its presence will have been taken into account by the speaker in formulating their utterance for that addressee. 
Thus, when the most publicly obvious construal of a referent's location is that it is 'here' for a given speaker, then that speaker should not encode it as 'not here', and therefore must use the semantically general demonstrative $n i i^{4}$.

CASE 1: speaker's here-space perimeter includes referent, excludes addressee.

The clearest examples are where the speaker is actually holding or otherwise manipulating an object.

(5)

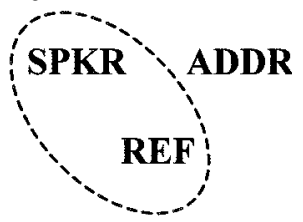

Figure 10 shows the merchant from previous examples (Figs. 3, 4, and 6) sitting on her market bench at her cutting block. The merchant has placed on the block a piece of meat that the customer has selected, and is now going to ask the customer whether the meat is to be sliced into pieces. She index-finger points to the meat (with her fingertip almost touching it), saying 'Nii ${ }^{4}$ one, should I slice in pieces?'.

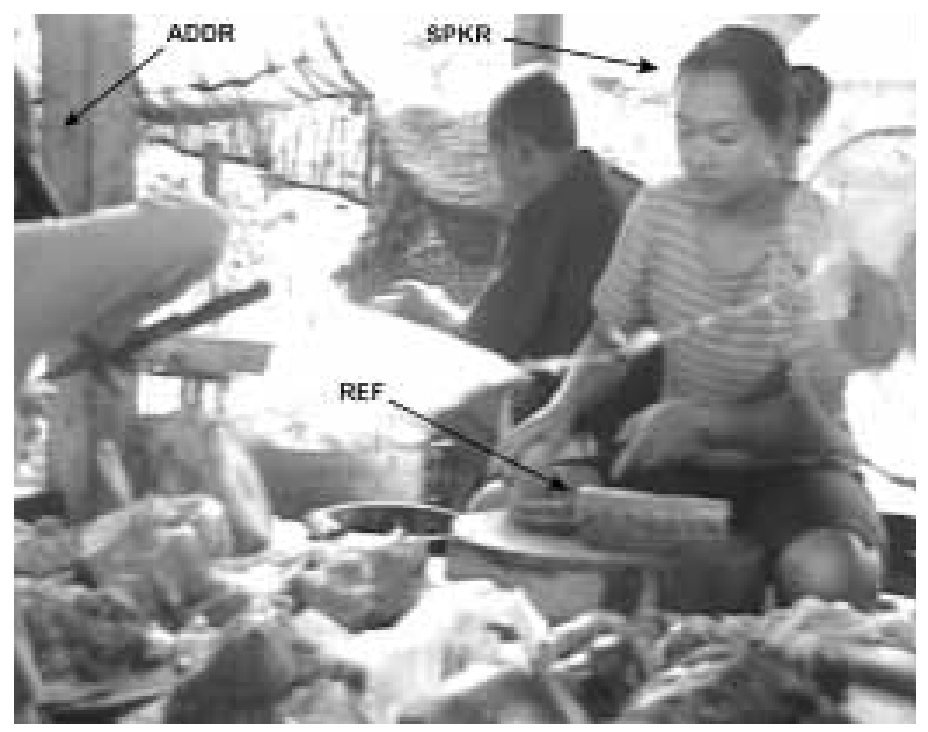

FIGURE 10. 'Nii ${ }^{4}$ one, should I slice in pieces?'

Informants are unanimous that the speaker could not have used $n a n^{4}$ here. Not only is the referent in the center of a currently dominant engagement area, but it is the very focus of the dominant engagement itself. Since this is clear to both speaker and addressee, the speaker has no reason to encode the referent as something 'not here'. Note that this is not due to the objectively measurable spatial proximity of the referent to the speaker. In a different interactional situation, an object just as close to the speaker could indeed be encoded, by $n a n^{4}$, as something 'not here' (see Fig. 3).

CASE 2: Speaker's here-space perimeter includes referent and addressee.

Often a referent is the focus of the speaker's AND hearer's joint attention, thus a central part of what defines a shared engagement area, and, in turn, a shared herespace. 
(6)

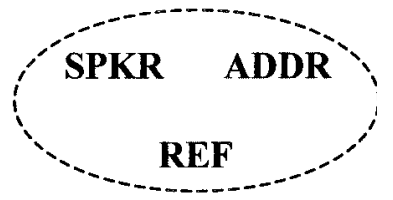

Figure 11 shows two adults and a small child in a classic joint attention scene. The child has a set of plastic animal figures, which she has set out on the floor between the three. As the man looks on, the woman asks the child 'Which one do you like?'. The child indicates the one she likes by touching it. The woman then points to the same figure, asking 'You like $n i i^{4}$ one?'.

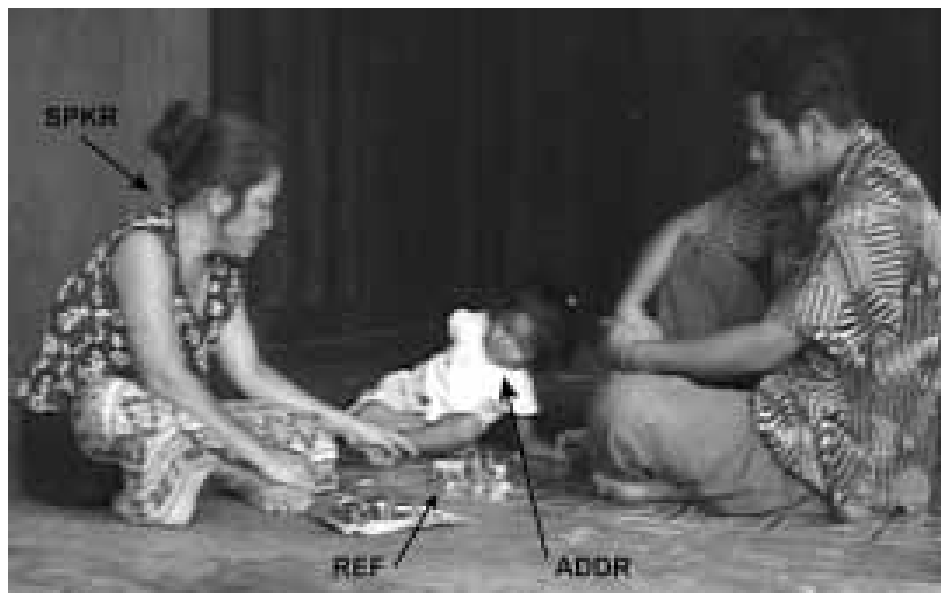

FIGURE 11. 'You like $n i i^{4}$ one?'

The engagement area these interlocutors have created has the referent at its physical and attentional center. The specification 'not here' is inapplicable, and so the semantically general demonstrative $n i^{4}$ is used.

Figure 12 shows a man and a woman harvesting lettuce from a market garden. They are each holding a knife, and the woman is carrying some already harvested lettuce, while the man is doing the cutting. They have not yet harvested enough for their current requirements, and at this moment are jointly attending to the garden bed, considering which rows of lettuce to cut next. The woman says, using the knife as a pointer, 'Nii' row, $n i i^{4}$ row, and that'll be enough', as the man motions to grab the lettuce plants and begin cutting.

This joint attentional scene puts the man, the woman, and the referent (the rows of lettuce) in one and the same engagement area, where the interlocutors share attentional focus on the referent, and, in turn, share one and the same here-space. Again, a specification of 'not here' would be inapplicable, and so the semantically general demonstrative $n i i^{4}$ is used.

6.3. Summary. $\mathrm{Nii}^{4}$ encodes an intensional meaning consisting onLy of the simple demonstrative meaning DEM (specifying that the reference of what it marks is expected by the speaker to be recoverable by the addressee, given certain common ground). It lacks any specification of the spatial location of the referent. But it often picks up an INFERRED meaning 'here' by paradigmatic opposition to the available more semantically specific term $n a n^{4}$, which ENCODES 'not here'. This is revealed by its use in two main 


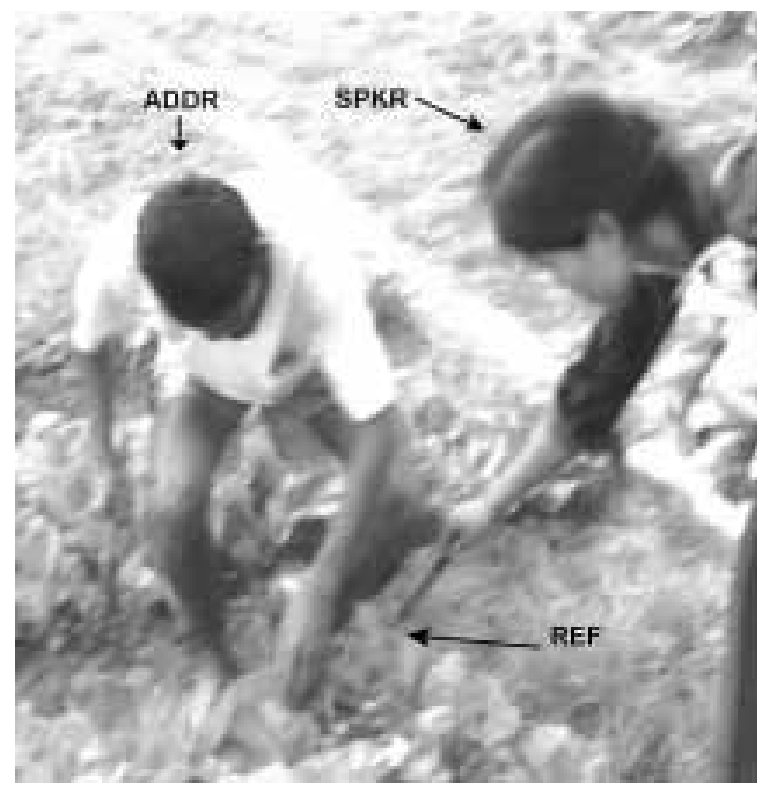

FiguRE 12. 'Nii ${ }^{4}$ row, nii $^{4}$ row, and that'll be enough.'

types of situations. In the first type of situation, there is no particularly salient perimeter of the speaker's here-space in the interaction (for example when the interaction is spatially diffuse), rendering an explicit reference to 'not here' irrelevant to the referential coordination task at hand. In the second type of situation, the perimeter of the speaker's here-space is salient in the interaction AND the referent is saliently within that perimeter (with subtypes in which the addressee is included, and not included, respectively, in the speaker's here-space). This situation rules out the possibility of encoding the referent (by $n a n^{4}$ ) as 'not here', leaving the semantically general term $n i i^{4}$ the only possibility.

7. AddResSee location, SPEAKER-ADdRESSEE DyNAMics, AND COMMON GROUND. Some demonstrative systems (e.g. systems with three or more elements) are reported to be 'person-oriented', where 'the location of the hearer serves as [a] reference point' for 'the location of the referent' (Diessel 1999:50, cf. p. 39, Anderson \& Keenan 1985:284). I have argued that the Lao two-term demonstrative system is, in semantic terms, SPEAKER oriented, in that the semantic distinction between the demonstratives is anchored in the speaker origo. I have also shown, however, that addressees contribute to spatial and interactional dynamics, and can thereby play a crucial role in influencing speakers' construal of the relevant spaces, and in turn determine which demonstrative is used. ${ }^{22}$ Another relevant factor affecting speakers' choices of demonstrative is not just their own construal of interactional space, but, just as importantly, their model of how ADDRESSEES expect messages to be tailored for them. I have mentioned already that speakers frame their linguistic choices under the assumption of a maxim of recipient design (Sacks \& Schegloff 1979). In all the examples described here, whether it is an engagement area, some physical obstacle, or some culturally conventional barrier which determines a here-space perime-

\footnotetext{
22 Özyürek (2000) argues that addressee location has an effect on the nature of 'shared space', and, in turn, on representational gestures. Clark (1996) argues forcefully for consideration of the addressee in our most general understanding of how communication works.
} 
ter, what matters is speakers' confidence that addressees will be able to model the speaker's intended construal of here-space - that is, the construal an addressee believes he or she is 'intended to infer on the basis of common ground' (Clark et al. 1983:257). Speakers tailor their utterances so that addressees are not required to make reference to information that the speaker knows or assumes they do not have access to. In turn, addressees EXPECT speakers' utterances to be tailored so as not to depend on information that is not assumed by speakers to be already shared with addressees. In the kinds of interactional situations examined here, the physical LOCATION of an addressee can determine the availability (i.e. by visual or other perceptual access) of certain information, and in turn, on speaker-addressee common ground, and in turn on a speaker's choice of demonstrative determiner. ${ }^{23}$ Thus, addressee location plays a crucial role in the selection of demonstratives, not only due to addressees' part in affecting the status of shared space (e.g. by physically or interactionally contributing to the establishment of speakers' here-space perimeters), but also due to their part in determining how speakers' messages are designed. And none of this entails any reference to the addressee in the semantics. ${ }^{24}$

The following example is illustrative of the pragmatic effect that speaker location can have on demonstrative selection. In Figure 13a, the hat woman has picked up a cabbage in her hand, and asks the younger merchant (see Fig. 7, above) the price, saying 'Nii ${ }^{4}$ one, how much?'. By holding it up, she is positioning the cabbage for the attention of the younger merchant (Clark 2003).

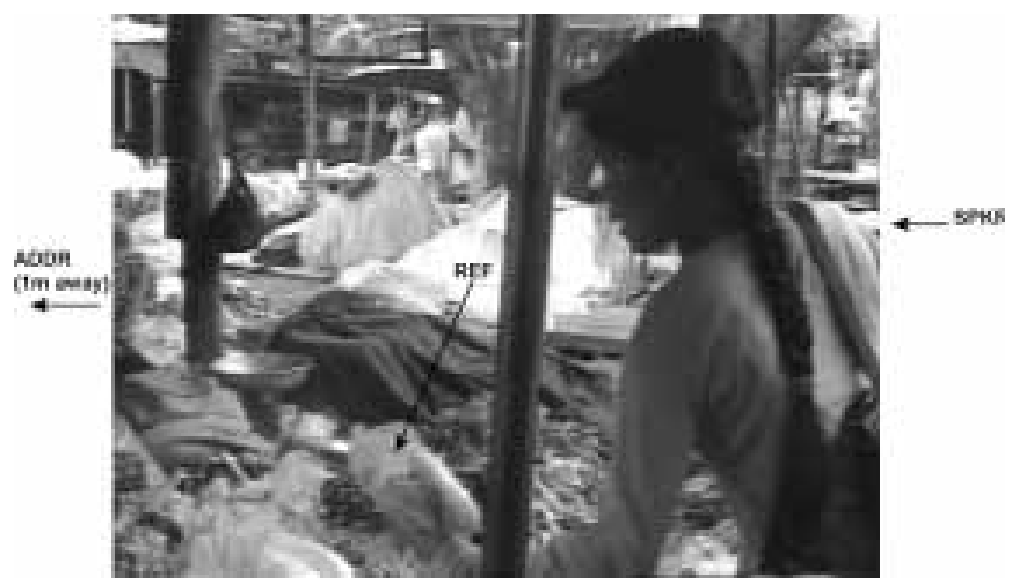

FIGURE 13a. 'Nii' one, how much?'

The addressee, standing behind the market stall, does not know the price. The older merchant, who in fact runs the stall, is at this moment some fifteen meters away from

\footnotetext{
${ }^{23}$ It is therefore worth regarding with caution the status of parameters such as 'visibility' or 'access' as SEMANTIC (i.e. encoded) elements of demonstrative systems (Anderson \& Keenan 1985:290, Diessel 1999: 41-42).

${ }^{24}$ This is not to say that addressees cannot be referred to in the semantics of demonstrative systems. Özyürek and Kita (2001; cf. Kita \& Dickey 1998:65-66) argue that the Turkish demonstrative su, traditionally referred to as encoding medial distance (in opposition to proximal $b u$ and distal $o$ ), in fact encodes the nonattention of the addressee to the referent. Thus, a referent of $s u$ is 'something you (the addressee) are not attending to now'.
} 
her stall (behind and to the right of the younger merchant), engaged in conversation with another stall owner in a neighboring stall. The younger merchant turns back to her right, calling to the older merchant 'How much is $n i i^{4}$ one?' ${ }^{25}$ This is the utterance of interest here.

This example is important because it allows only the semantically more general term $n i i^{4}$. When consultants are shown this scene, they are unanimously adamant that the speaker in Fig. 13b could NOT have used distal $\mathrm{nan}^{4}$ when addressing the older woman, standing far from the market stall pictured. At the same time, consultants are agreed that if the addressee had been the HAT WOMAN, holding the referent in her hand, then the speaker could have used either $n a n^{4}$ or $n i i^{4}$. This may be contrasted with Fig. 4, in which the speaker uses distal $n a n^{4}$ in a situation almost identical to this one in terms of the purely spatial geometry of speaker, addressee, and referent placement.

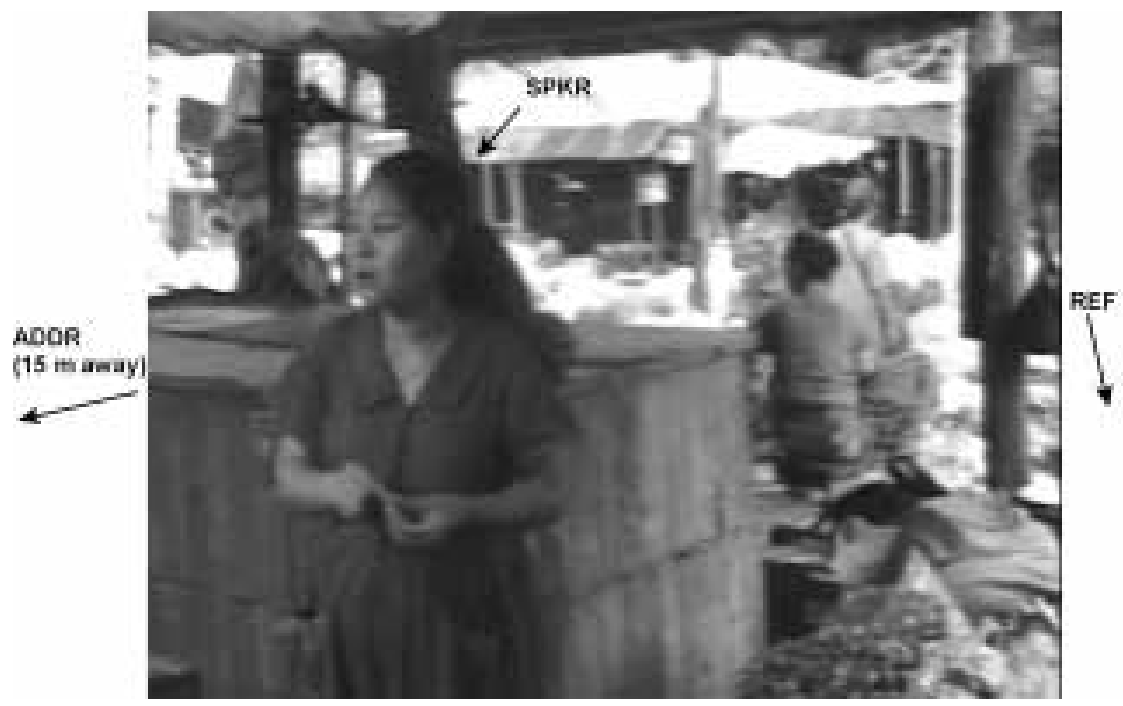

FIGURE 13b. 'How much is $n i i^{4}$ one?'

If the addressee in Fig. 13b had been the hat woman, and if the speaker had used distal $\operatorname{nan}^{4}$, this would have suggested a construal of the hat woman's here-space as being closed to the speaker, and therefore that the cabbage (undeniably in the hat woman's here-space) was, for the speaker, 'not here'. As shown in examples such as Fig. 4, 6, and 7, this would be in no way unusual. But given the interactional and physical geometry of the speaker and addressee combination in Fig. 13b, consultants find it inconceivable that the speaker would have encoded the cabbage as something 'not here'. It would simply be bad recipient design. The speaker has not at this point been interactionally engaged in any way with the older merchant. Thus, speaker and addressee do not currently share any common ground concerning contingently active spatial closure. The most salient closure that the speaker and addressee in Fig. 13b can assume to be common ground is the perimeter provided by default in the context, namely the conventionally defined closures separating each individual market stall from the next. In this context, the market-stall perimeters are default candidates for here-

\footnotetext{
${ }^{25}$ Note that the pillar on the left of Fig. 13a is the same pillar as the one to the right of Fig. 13b. This gives an idea of the distance between speaker and referent (about two meters).
} 
space perimeters. The notion of speaker's 'here' that the speaker can expect to be most saliently available to the addressee is thus 'here at this market stall'.

This is a case of interlocutors jointly solving a coordination problem with a 'Schelling choice' based on assumptions about common ground (Schelling 1960:54). Even though specific interactional factors could have contributed to the establishment of a locally divisive here-space perimeter WITHIN the market stall area (dividing the speaker's space from the space of the woman holding the referent and thus putting the referent in a place 'not here' for the speaker), the addressee in the case of Fig. 13b (the older woman, out of sight) could have had no knowledge of those factors, since she was not near the scene. The speaker knew this, and the older woman-as addressee-knew that the speaker knew this. Accordingly, the addressee expected the speaker to have taken this common ground into account in designing the utterance (Clark et al. 1983:257). This claim is supported by consultants' unanimous rejection of distal $\operatorname{nan}^{4}$ as a possibility for the scene in Fig. 13b.

8. Appropriating the here-SPACE Perimeter fOr CONTRAST BETWEen tWo REFERENTS. In many languages, different demonstratives may be used to express contrast between two possible referents (e.g. English thIS one, not THAT one). Often, a Lao speaker will use a single demonstrative to refer to two things contrastively (where the contrast is achieved nonverbally, for example, by finger-pointing). There are cases, however, in which $n i i^{4}$ and $n a n^{4}$ are used contrastively, the basic principle being to arbitrarily place the here-space perimeter between the two objects, as long as the objects are viewed on an away-going axis.

8.1. ReCRUITING THE OUTWARD-RADIATING BORDER BETWEEN 'HERE' AND 'NOT HERE'. Lao speakers often use $n i i^{4}$ and $n a n^{4}$ to distinguish contrastively between two objects that are placed at different distances on a line radiating out from the speaker. Figures $14 \mathrm{a}-\mathrm{d}$ show a sequence in which two women are discussing two newly purchased hand towels, which are the focus of their joint attention. The speaker, on the right, indicates contrasts between the two towels, first in terms of price, and second in terms of thick-

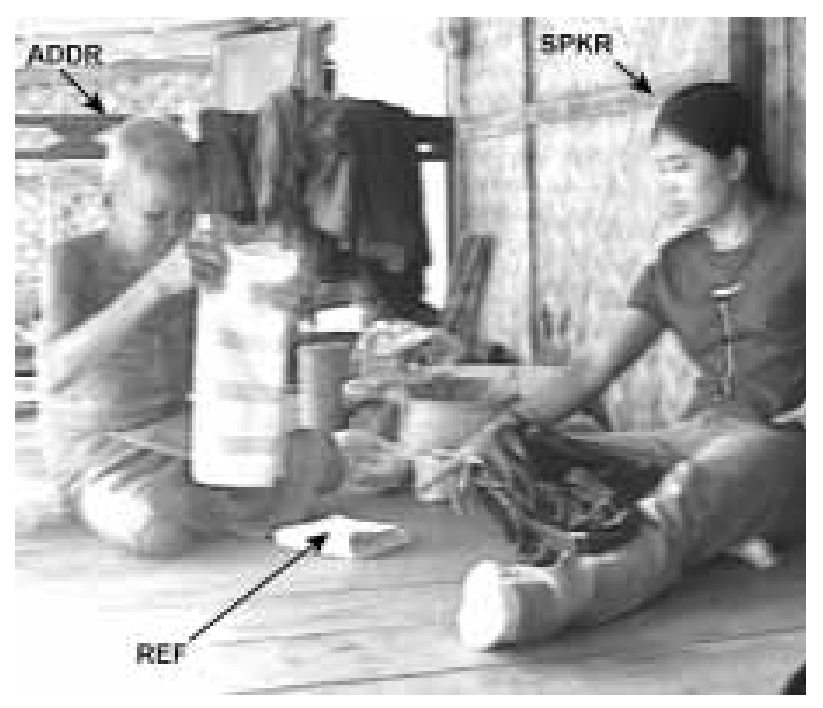

FIGURE 14a. 'Nii ${ }^{4}$ one cost 4000.' 


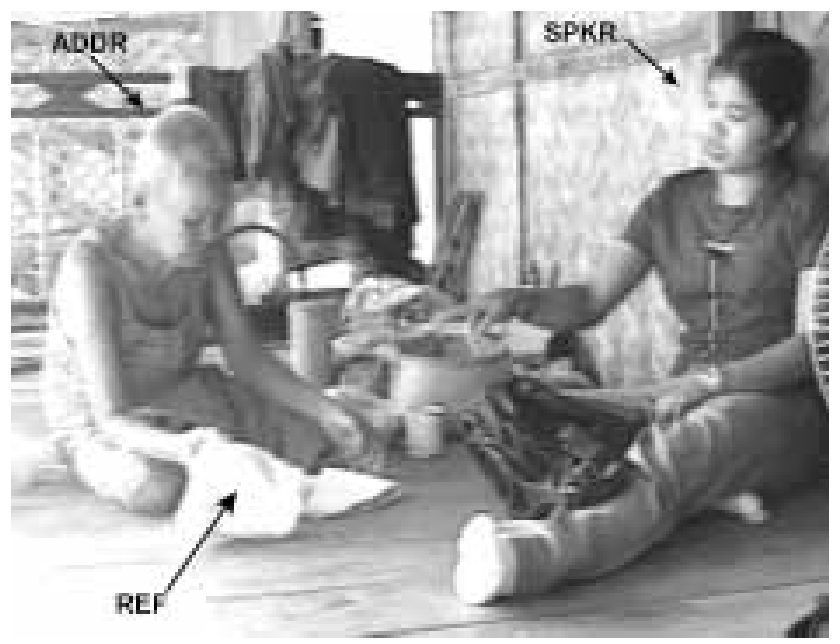

FIGURE 14b. 'Nan ${ }^{4}$ one cost 7000 .'

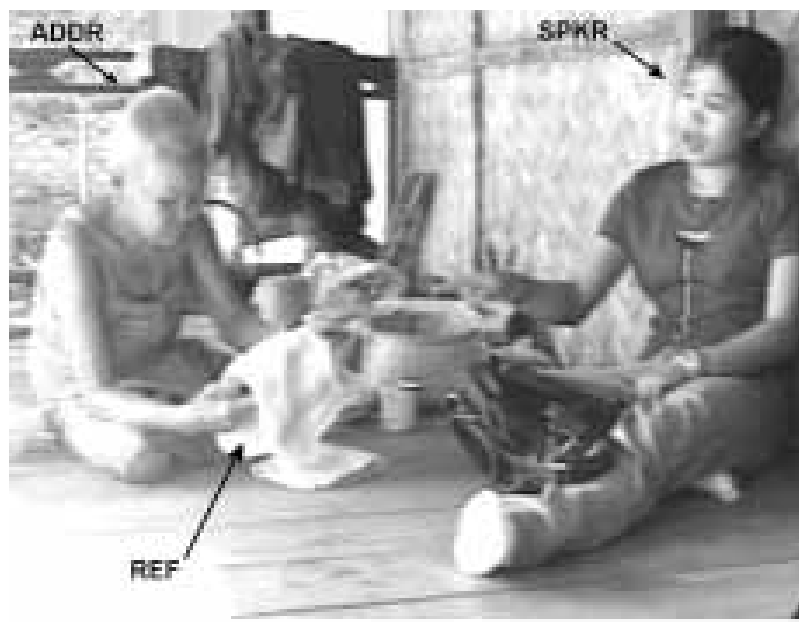

FIGURE 14c. 'Nan' ${ }^{4}$ one is thicker ...'

ness. As she speaks, she points with her index finger to the relevant towel, in the sequence shown by Figs. 14a-d.

The speaker makes contrastive reference to the towels by arbitrarily setting the perimeter of here-space as bisecting the outward-radiating line from one towel to the next, referring to the further towel as the one 'not here' (by using $n a n^{4}$ ), and using the unmarked $n i i^{4}$ to refer to the remaining towel (the nearer one). This strategy is common when a pair of objects are in this kind of alignment: nearer to and further from the speaker, respectively, on a line radiating out from the deictic center. This is illustrated schematically in 7 .

(7)

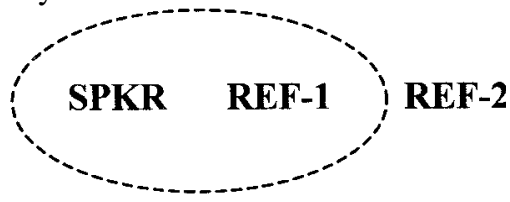




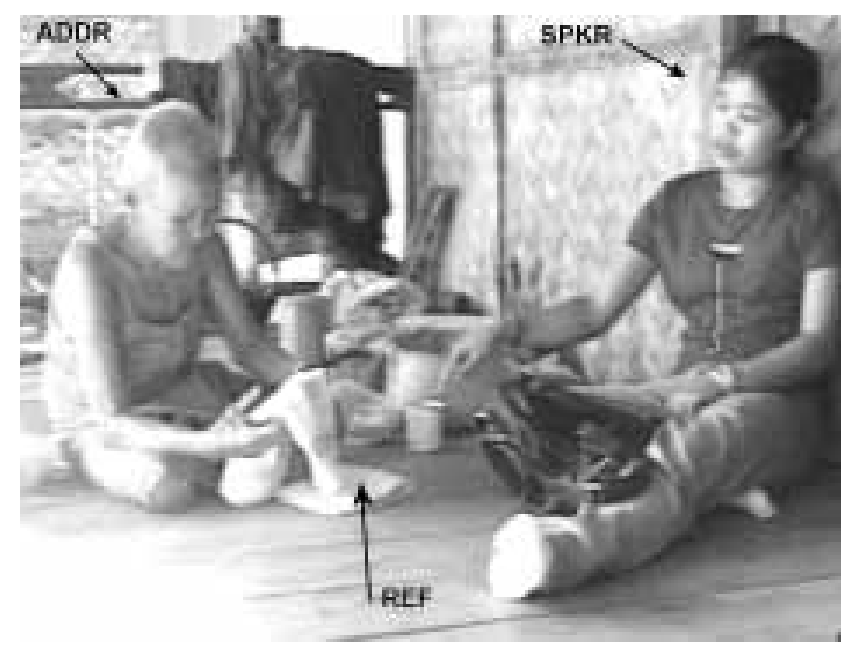

Figure 14d. ' $\ldots$ than nii $^{4}$ one.'

This is a clear case in which relative distance does determine the selection of demonstratives, yet without being encoded semantically. As discussed in $\S 3.2$, the extension of 'here' is intensionally discrete yet extensionally elastic. Once a perimeter of herespace is set, something outside it will naturally be 'far' in comparison to something inside it. It is perhaps because 'near' and 'far' are scalar notions that people have regarded them as the operative distinction in demonstrative semantics (see Kemmerer 1999).

When objects are arrayed crosswise, not on that outwards-radiating line, then $n i i^{4}$ and $n a n^{4}$ are generally not used contrastively, as the example in Figure 15 shows. In Fig. 15, two women discuss how to operate a washing machine (refer back to Fig. 5, above). In a twenty-second sequence, fourteen demonstrative references_all nii ${ }^{4}$ - are made to various buttons, as the two women maintain joint attention on the array of buttons, continually touch-pointing throughout. They are discussing which buttons are to be pressed at which times during the washing machine's cycle.

In this case the speakers are unable to use the contrastive strategy seen in the previous example, whereby the here-space perimeter was deliberately set to bisect an outwardradiating line from self to one object and to the next one.

8.2. USING DISTAL $n^{4} n^{4}$ AS 'THE OTHER ONE' WHERE A BINARY CHOICE IS SALIENT. There are contexts in which $n i i^{4}$ and $n a n^{4}$ are used contrastively when the objects in question are NOT in a line radiating away from the speaker. If two referents to be contrasted are a salient pair of parts of a thing (identical in some relevant sense), one may be referred to by $\operatorname{nan}^{4}$, with a reading translatable into English as 'the other one'. The remaining referent of the two is referred to, by contrast, with $\mathrm{nii}^{4}$. I observed an instance in which a small child was trying to get up onto a tractor cart, and she was having trouble doing so, because she was trying to get on at the wrong end. The child's mother was sitting, watching, about five meters away, with the cart sitting crosswise, that is, with the line from one end of the cart to the other exactly perpendicular to the line radiating out to the cart from her deictic center. Neither end of the cart was closer to the speaker than the other. Nevertheless, she said to the child 'No, get on at nan end!', meaning 'No, get on at the other end'. One explanation is that the speaker is 


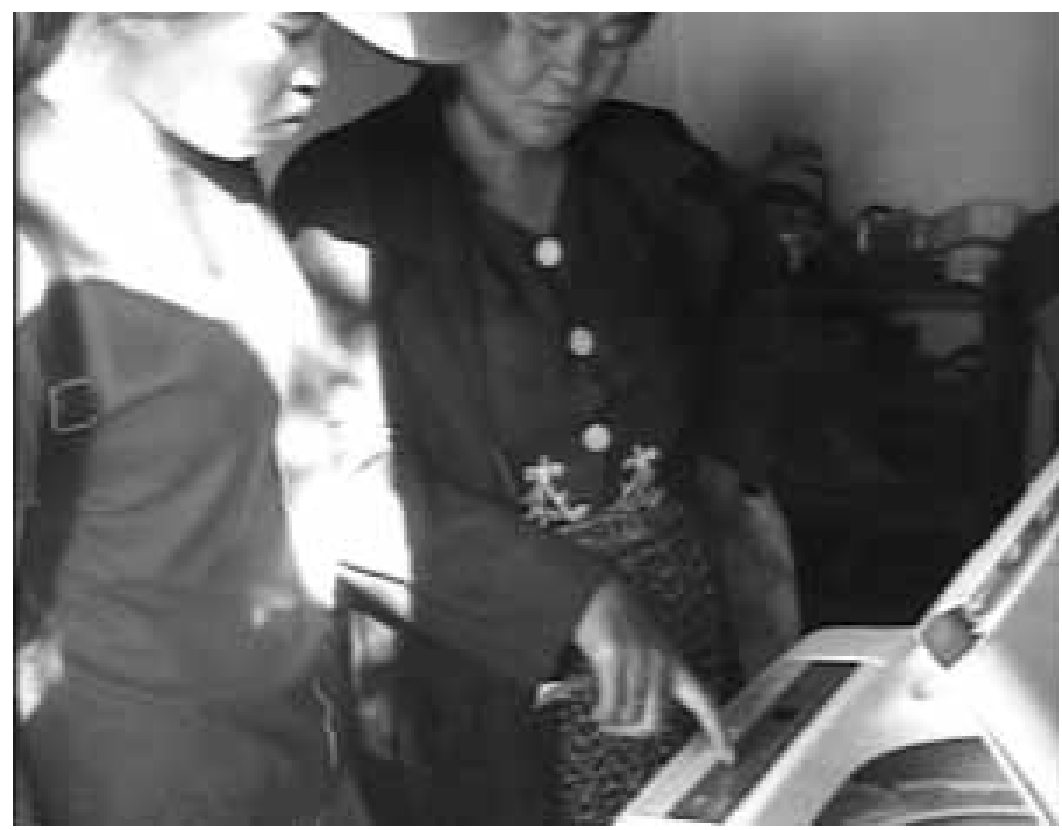

FIGURE 15. Fourteen uses of $n i i^{4}$ (none of $n a n^{4}$ ) in a twenty-second sequence of reference to different control buttons.

TRANSPOSING her deictic center to that of the child (Bühler 1982[1934], Haviland 1993). There are two ends to the cart, and one is closer to the addressee than the other. It is the one 'not here' from the addressee's point of view which is referred to by distal $n^{4}{ }^{4}$.

9. Conclusion. Standard typologies of demonstratives would lead one to expect a two-term system of demonstrative determiners such as Lao $n i i^{4}$ and nan ${ }^{4}$ to encode a simple spatial distinction proximal versus distal. But the data described in this study have shown that such an analysis lacks important insights. For instance, it would not tell us why the 'proximal' demonstrative can refer to things both closer and further away than things which may be referred to by the 'distal' term. The standard analysis both overestimates and ill defines the semantic content of these expressions, and fails to acknowledge sufficient richness in the contribution of context and pragmatic implicature to demonstrative usage. The advantage of the approach taken here over an analysis based on a symmetrical opposition of distance-marking is that it shows how a stable and discrete intensional value can map onto greatly variable analogue extensional values. This cannot be understood without acknowledging a distinction between discrete, conventionally encoded intensional meaning and other aspects of meaning arising in and from context. Semantics and pragmatics are distinct, but they must be treated as equal parts in a whole analysis.

To approach a rich crosslinguistic account of how demonstratives function, we need analyses based on examples from genuine spontaneous usage, ideally collected on video. This provides the necessary amount of detailed contextual information for teasing out what is semantically encoded from what is contextually given and/or pragmatically implicated. Grammatical typology suffers enough from its opportunistic diet of tidbits found in available language descriptions, which often fail to provide adequate detail 
and/or justification for the analyses proposed. When it comes to SEMANTIC typology in particular, the situation is worse. Authors of reference grammars simply do not have the means to treat semantic and pragmatic problems in sufficient detail. When one's objective is crosslinguistic generalization about matters of fine semantic and pragmatic detail, secondary sources seldom suffice. An adequate semantic typology demands that the questions be framed BEFORE the linguist sets off for the field.

I summarize the findings of this investigation as follows. Of the two Lao demonstrative determiners, neither encodes information about distance, and only one encodes information about location. Neither $n i i^{4}$ nor $n a n^{4}$ tells the addressee 'how far away' a referent is, and only nan ${ }^{4}$ says 'where' it is. Pragmatic inference alone gives rise to the association of $n i i^{4}$ with things 'NEAR speaker' and/or 'here', and nan ${ }^{4}$ with things 'FAR from speaker'. What is shared by the two forms is a core primitive demonstrative meaning, a specification that a speaker is referring to something that he or she assumes is salient enough in the common ground to be uniquely identifiable by an addressee as the referent the speaker is referring to. The two demonstrative determiners interact system-internally, forming an informativeness scale, with one 'weak' or semantically general member, and one 'strong' or semantically specific member, the latter being more informative. Their semantic meanings are highly abstract and general but nevertheless stable and specifiable. Hand in hand with this, there are pragmatic factors that can be systematically described. This study has shown that factors such as distance of referent from speaker, location of addressee with respect to referent, and visibility of referent to speaker and/or addressee can each play a crucial role in the use of demonstratives, yet without being referred to in their semantics. Lao speakers' choices between the two available demonstratives are influenced by conceived extensions of here-space. These conceptions are determined, in turn, on the basis of pragmatic factors emergent in the dynamic interactional situation, including physical barriers, perimeters of engagement area created by interlocutors' manual and attentional focus, and conceived 'gravitational pull' between interlocutors and objects, among other things. In addition, given the omnipresence of an interactional maxim of RECIPIENT DESIGN, speakers also take into account their addressees' presumed access to information relevant for inferring the extension of the speaker's conceived here-space. In this way, ALL demonstratives are вотн speaker-anchored and addressee-anchored. To what extent the contributions of these contextual and interactional factors are culturally universal remains to be seen, but considerations of this kind need to be included in further cross-linguistic research on the semantics of demonstratives.

In conclusion, I propose that this analysis of Lao $n i i^{4}$ and nan $^{4}$ provides an alternative to standard analyses of simple demonstrative systems, which assume semantic symmetry based on an encoding of distance, 'near' versus 'far'. My analysis has accounted for a wide range of examples from spontaneous situated interaction. The burden for other analyses is now to show that they can account for data of similar richness. I submit that upon close inspection, analyses like the present one could be valid for most, if not all, other multiterm demonstrative systems.

\section{REFERENCES}

Anderson, Stephen R., and Edward L. Keenan. 1985. Deixis. Language typology and syntactic description, ed. by Timothy Shopen, vol. 3. 259-308. Cambridge: Cambridge University Press.

Bourdieu, PierRe. 1977. Outline of a theory of practice. Cambridge: Cambridge University Press.

BüHLER, KARL. 1982[1934]. The deictic field of language and deictic words. (Translated 
excerpt from Sprachtheorie: Die Darstellungsfunktion der Sprache, 1934.) Speech, place, and action, ed. by Robert J. Jarvella and Wolfgang Klein, 9-30. Chichester: John Wiley.

CARnaP, Rudolf. 1947. Meaning and necessity. Chicago: University of Chicago Press.

CASAd, Eugene H. 1988. Conventionalization of Cora locationals. Topics in cognitive linguistics, ed. by Brygida Rudzka-Ostyn, 345-78. Amsterdam and Philadelphia: John Benjamins.

Chao, Yuen Ren. 1930. A system of tone letters. Le maître phonétique, troisième série, $30.24-27$.

Clark, Herbert H. 1996. Using language. Cambridge: Cambridge University Press.

Clark, Herbert H. 2003. Pointing and placing. Pointing, ed. by Sotaro Kita, 243-68. Mahwah, NJ: Lawrence Erlbaum.

Clark, Herbert H.; Robert Schreuder; and Samuel Buttrick. 1983. Common ground and the understanding of demonstrative reference. Journal of Verbal Learning and Verbal Behavior 22.245-58.

D'AndRade, Roy D. 1987. A folk model of the mind. Cultural models in language and thought, ed. by Dorothy Holland and Naomi Quinn, 112-48. Cambridge: Cambridge University Press.

Diessel, Holger. 1999. Demonstratives: Form, function, and grammaticalization. Amsterdam and Philadelphia: John Benjamins.

ENFieLD, N. J. 2000. The theory of cultural logic: How individuals combine social intelligence with semiotics to create and maintain cultural meaning. Cultural Dynamics 12.35-64.

Fillmore, Charles J. 1982. Towards a descriptive framework for spatial deixis. Speech, place, and action, ed. by Robert J. Jarvella and Wolfgang Klein, 31-59. Chichester: John Wiley.

Fillmore, Charles J. 1997[1971]. Lectures on deixis. Stanford, CA: CSLI Publications.

GodDARD, CLIFF. 1998. Bad arguments against semantic primitives. Theoretical Linguistics $24.129-56$.

GoffMAn, ERving. 1963. Behavior in public places. New York: Free Press.

Goody, Esther N. (ed.) 1995. Social intelligence and interaction: Expressions and implications of the social bias in human intelligence. Cambridge: Cambridge University Press.

Grice, H. PAUl. 1975. Logic and conversation. Syntax and semantics, vol. 3: Speech acts, ed. by P. Cole and J. L. Morgan, 41-58. New York: Seminar Press.

Grice, H. Paul. 1989. Studies in the way of words. Cambridge, MA: Harvard University Press.

Halliday, Michael A. K., and Ruqaiya Hasan. 1976. Cohesion in English. London: Longman.

Hanks, William. 1990. Referential practice: Language and lived space among the Maya. Chicago: University of Chicago Press.

Haviland, John. 1993. Anchoring, iconicity, and orientation in Guugu Yimithirr pointing gestures. Journal of Linguistic Anthropology 3.3-45.

Himmelmann, Nikolaus P. 1996. Demonstratives in narrative discourse: A taxonomy of universal uses. Studies in anaphora, ed. by Barbara Fox, 205-54. Amsterdam: John Benjamins.

Hockett, Charles F. 1987. Refurbishing our foundations: Elementary linguistics from an advanced point of view. Amsterdam and Philadelphia: John Benjamins.

Kemmerer, DAVID. 1999. 'Near' and 'far' in language and perception. Cognition 73.35-63.

Kendon, AdAm. 1977. Studies in the behavior of social interaction. Bloomington, IN: Indiana University and Lisse: Peter de Ridder.

Keysar, Boaz; Dale Barr; Jennifer A. Balin; and Jason S. Brauner. 2000. Taking perspective in conversation: The role of mutual knowledge in comprehension. Psychological Science 11.32-38.

Kita, Sotaro, and Laura Walsh Dickey (eds.) 1998. Max Planck Institute for Psycholinguistics annual report 1998. Nijmegen: Max Planck Institute for Psycholinguistics.

LAKOFF, GEORGE. 1987. Women, fire and dangerous things: What categories reveal about the mind. Chicago: Chicago University Press.

LaKofF, RoBIN. 1974. Remarks on this and that. Chicago Linguistics Society 10.345-56. 
LANGACKER, Ronald W. 1987. Foundations of cognitive grammar, vol. 1: Theoretical prerequisites. Stanford, CA: Stanford University Press.

LANGACKER, RONALD W. 1997. The contextual basis of cognitive semantics. Language and conceptualization, ed. by Jan Nuyts and Eric Pedersen, 229-52. Cambridge: Cambridge University Press.

Lee, Penny. 1996. The Whorf theory complex: A critical reconstruction. Amsterdam and Philadelphia: John Benjamins.

Levinson, StePhen C. 1995. H. P. Grice on location on Rossel Island. Berkeley Linguistics Society $25.210-24$.

Levinson, STEPHEN C. 1997. From outer to inner space: Linguistic categories and nonlinguistic thinking. Language and conceptualization, ed. by Jan Nuyts and Eric Pedersen, 13-45. Cambridge: Cambridge University Press.

Levinson, STEPHEN C. 2000. Presumptive meanings: The theory of generalized conversational implicature. Cambridge, MA and London: MIT Press.

Levinson, Stephen C. 2001. Maxim. Key terms in language and culture, ed. by Alessandro Duranti, 139-42. London: Blackwell.

LEwIS, DAvid K. 1969. Convention: A philosophical study. Cambridge, MA: Harvard University Press.

Lyons, JoHn. 1968. Introduction to theoretical linguistics. Cambridge: Cambridge University Press.

Lyons, John. 1977. Semantics. Cambridge: Cambridge University Press.

ÖZYÜREK, AsLI. 2000. The influence of addressee location on spatial language and representational gestures of direction. Language and gesture, ed. by David McNeill, 64-83. Cambridge: Cambridge University Press.

ÖZYÜREK, AsLI, and Sotaro KITA. 2001. Interacting with demonstratives: Encoding of joint attention as a semantic contrast in Turkish and Japanese demonstrative systems. Istanbul and Nijmegen: Koç University and Max Planck Institute for Psycholinguistics, MS.

Peirce, Charles Sanders. 1965/1932. Collected papers of Charles Sanders Peirce, vol. 2: Elements of logic, ed. by Charles Hartshorne and Paul Weiss. Cambridge, MA: Belknap Press of Harvard University Press.

Sacks, Harvey, and Emanuel A. Schegloff. 1979. Two preferences in the organization of reference to persons in conversation and their interaction. Everyday language: Studies in ethnomethodology, ed. by George Psathas, 15-21. New York: Irvington.

SCHEFlen, Albert E. 1976. Human territories: How we behave in space-time. Englewood Cliffs, NJ: Prentice-Hall. (Written with Norman Ashcraft.)

Schelling, Thomas C. 1960. The strategy of conflict. Cambridge, MA: Harvard University Press.

van Geenhoven, Veerle, and Natasha Warner (eds.) 1999. Max Planck Institute for Psycholinguistics annual report 1999. Nijmegen: Max Planck Institute for Psycholinguistics.

Wierzbicka, AnNa. 1972. Semantic primitives. Frankfurt: Athenäum.

WierzBicKa, AnNA. 1980. Lingua mentalis. Sydney: Academic Press.

Wierzbicka, AnNA. 1990. 'Prototypes save': On the uses and abuses of the notion of 'prototype' in linguistics and related fields. Meanings and prototypes: Studies in linguistic categorization, ed. by Savas L. Tzohatzidis, 347-67. London: Routledge and Kegan Paul.

WierzBicka, AnNA. 1996. Semantics: Primes and universals. New York: Oxford University Press.

WiLKINS, DAVID P. 1999. Demonstrative questionnaire: 'THIS' and 'THAT' in comparative perspective. Manual for the 1999 field season, ed. by David P. Wilkins, 1-24. Nijmegen: Language and Cognition Group, Max Planck Institute for Psycholinguistics.

Wilkins, David P., and Deborah Hill. 1995. When 'go' means 'come': Questioning the basicness of motion verbs. Cognitive Linguistics 6.209-59.

Max Planck Institute for Psycholinguistics

[Received 24 October 2001;

Postbus 310 accepted 27 August 2002]

6500 AH Nijmegen

The Netherlands

[Nick.Enfield@mpi.nl] 